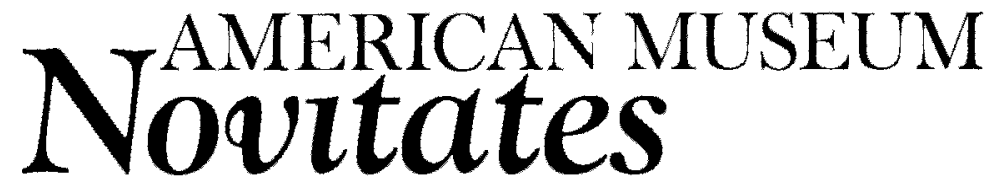

PUBLISHED BY THE AMERICAN MUSEUM OF NATURAL HISTORY CENTRAL PARK WEST AT 79TH STREET, NEW YORK, NY 10024 Number 3543, 22 pp., 16 figures

December 7, 2006

\title{
Two New Species of Sponge-Dwelling Snapping Shrimp from the Belizean Barrier Reef, with a Synopsis of the Synalpheus brooksi Species Complex
}

\author{
KENNETH S. MACDONALD III ${ }^{1}$ AND J. EMMETT DUFFY ${ }^{2}$
}

\begin{abstract}
Two new species of sponge-dwelling snapping shrimp in the genus Synalpheus are described. Synalpheus carpenteri is based on specimens collected from the Belizean Barrier Reef, the Exuma Islands of the Bahamas, and the Atlantic Coast of Panama, while Synalpheus ruetzleri is based on specimens collected from the Belizean Barrier Reef and the Atlantic Coast of Panama. Both species belong to a group of closely related shrimp (the "Synalpheus brooksi complex") that includes Synalpheus brooksi, Synalpheus bousfieldi, Synalpheus chacei, and possibly additional undescribed species. All species in the complex are remarkably similar in morphology, but Synalpheus carpenteri is readily recognizable by its brilliant orange color in life, its habitation solely in sponges of the genus Agelas, its squat, wide-based telson, and the short lateral spines of its scaphocerite and basicerite. Synalpheus ruetzleri appears unique within the complex in possessing a well-developed blade on the scaphocerite. Specimens of Synalpheus brooksi and S. bousfieldi from Belize and other localities are also figured to facilitate separation of members of the brooksi complex.
\end{abstract}

\section{INTRODUCTION}

Snapping shrimp in the genus Synalpheus Bate, 1888 are diverse components of the cryptic fauna of coral reefs and other tropical marine ecosystems worldwide (Felder and Chaney 1979; Reed et al., 1982). The genus includes more than 150 species (Chace, 1988;
Ríos, personal obs.) that inhabit the interstices of coral rubble, the internal spaces of sponges, and, in the Indo-Pacific, the arms of crinoid echinoderms (Beebe, 1928; Pearse, 1932; Bruce, 1976; Duffy, 1992). These shrimp are small (usually $<2 \mathrm{~cm}$ in length) and reclusive and are often among the most abundant cryptofaunal macroinvertebrates in reef envi-

\footnotetext{
${ }^{1}$ Division of Invertebrate Zoology, American Museum of Natural History (kmacdonald@amnh.org).

${ }^{2}$ School of Marine Science and Virginia Institute of Marine Science, The College of William and Mary, Gloucester Point, VA (jeduffy@vims.edu).
} 
ronments (Pearse, 1932; Rützler, 1976). Despite their abundance and diversity, the systematic relationships and taxonomy of the genus Synalpheus remain poorly resolved.

In the western Atlantic, the genus Synalpheus is dominated by species in the Gambarelloides group (Coutière, 1909; Dardeau, 1984), a monophyletic clade (Morrison et al., 2004) that is largely endemic to that region. Species in the gambarelloides group are obligate spongedwellers that are characterized by a distinctive brush of long, thickly packed setae arranged in transverse parallel rows on the extensor surface of dactyl of the smaller first chela (Coutière, 1908, 1909). The distinctive setal brush is used to collect food from the surfaces of the sponge canals in which they live (Duffy, 2003).

Collections of West Atlantic Synalpheus during the last 15 years have revealed a complex of morphologically similar species in the Gambarelloides group that includes Synalpheus brooksi Coutière, 1909, Synalpheus bousfieldi Chace, 1972, Synalpheus chacei Duffy, 1998, and two additional species described here. Synalpheus brooksi is predominantly found in two common shallow-water sponges, Spheciospongia vesparium Lamark, 1814 and Lissodendoryx colombiensis Zea and van Soest, 1986, but it has also been collected infrequently from a variety of other sponges (personal obs.; Macdonald et al., 2005). In 1972, Chace described a closely related species, $S$. bousfieldi, that inhabits a wide diversity of sponges throughout the Caribbean (Chace, 1972; Dardeau, 1984; Macdonald et al., 2005). Both species have been considered highly variable morphologically, but recent work indicates that much of this variation is attributable to distinct, morphologically cryptic species, including $S$. chacei and the two new species in the brooksi complex described herein.

\section{MATERIALS AND METHODS}

Specimens were collected between 1988 and 2004 from sponges in the vicinity of Carrie Bow Cay on the Belize Barrier Reef, Central America $\left(16^{\circ} 48^{\prime} \mathrm{N}, 88^{\circ} 05^{\prime} \mathrm{W}\right)$, the San Blas Islands on the Caribbean coast of Panamá $\left(9^{\circ} 34^{\prime} \mathrm{N}, 78^{\circ} 58^{\prime} \mathrm{W}\right)$, and the Exuma Islands of the Bahamas $\left(23^{\circ} 46^{\prime} \mathrm{N}, 76^{\circ} 06^{\prime} \mathrm{W}\right)$. Most shrimp were collected alive from their host sponges by the authors and colleagues using scuba diving equipment. Sponges were identified whenever possible. Lists of material examined are not comprehensive; additional specimens in the VIMS collection also were examined. Type specimens and voucher material are deposited in the National Museum of Natural History, Smithsonian Institution, Washington, DC (USNM); the American Museum of Natural History (AMNH); and in the Virginia Institute of Marine Science, Gloucester Point, VA (VIMS). VIMS numbers listed refer to field specimen numbers. Measurements correspond to carapace length $(\mathrm{CL})$ in millimeters, taken from the most posterior edge of the carapace on the dorsal midline to the base of the rostrum. Specimens were figured using a camera lucida on a Wild M3C dissecting microscope or from digital photos taken by a Diagnostic Instruments Spot RT photo system using an Olympus BX50 light microscope.

\section{ORDER DECAPODA LATREILLE, 1802}

\section{FAMILY ALPHEIDAE RAFINESQUE, 1815}

GENUS SYNALPHEUS BATE, 1888

Synalpheus carpenteri, new species figures $1-7$

Synalpheus bousfieldi (in part), in Dardeau 1984: USNM 189150, fig. 10.

Synalpheus "bousfieldi A", in Morrison et al., 2004, and in Macdonald et al., 2005.

Holotype: कo (USNM 1092295, original VIMS 04CBC4201), Long Reef, Belize, from canals of Agelas clathrodes Schmidt, 1870. Carapace length (CL): $3.32 \mathrm{~mm}$.

AllotyPe: o (USNM 1092296, original VIMS 04CBC4202), Long Reef, Belize, from canals of same individual $A$. clathrodes as holotype. CL: $3.86 \mathrm{~mm}$.

PARATYPES: $q$ (AMNH Crustacea 18492, original VIMS 04CBC4203), Long Reef, Belize, from canals of same individual $A$. clathrodes as holotype. CL: $3.01 \mathrm{~mm}$. of (AMNH Crustacea 18493, original VIMS 04CBC4305), Long Reef, Belize, from canals of A. clathrodes. CL: $2.74 \mathrm{~mm}$.

Additional Specimens Examined: $q, \hat{\sigma}$ (USNM 1092297, 1092298, original VIMS 
96CBC3303-3304), Carrie Bow Cay, Belize, from canals of $A$. clathrodes. o (VIMS 98CBC0601), Curlew Reef, Belize, from canals of A. clathrodes. + (VIMS 98CBC3103), Carrie Bow Cay, Belize, from canals of Agelas dispar. + (VIMS 98CBC3301), Carrie Bow Cay, Belize, from canals of $A$. clathrodes. 2 s, + (VIMS 01LS0101, 0105-06), White Horse Rocks, Exuma Islands, Bahamas, from canals of $A$. clathrodes. 3 o, 5 o (USNM 1092299-1092306, original VIMS 01LS13011307,1309), G-spot, Exuma Islands, Bahamas, from canals of $A$. clathrodes. + , of (VIMS 01LS1501-02), G-spot, Exuma Islands, Bahamas, from canals of $A$. clathrodes.

Specimens examined and provisionally assigned to $S$. carpenteri. These individuals will herein be referred to as $S$. cf. carpenteri. $\delta: 5$ individuals (VIMS 93P1106), Aguadargana Reef, San Blas Islands, Panama, from canals of A. clathrodes. ㅇ, 2 \&े (VIMS 93P2609-10), Limones Reef, San Blas Islands, Panama, from canals of $A$. clathrodes. + , $\delta$ (VIMS 93P4703), Limones Reef, San Blas Islands, Panama, from canals of $A$. clathrodes. $q$ (VIMS 93P5306), Aguadargana Reef, San Blas Islands, Panama, from canals of $A$. clathrodes. 2 \%, ô (USNM 1092307-109309, original VIMS 92P6101-03), San Blas Islands, Panama, from canals of $A$. clathrodes. $\hat{\delta}$, $q$ (USNM 1092310-1092311, original VIMS 92P6903-04), Mamitupo Reef, San Blas Islands, Panama, from canals of $A$. clathrodes.

DESCRIPTION: Body form subcylindrical; carapace smooth, sparsely setose, with pterygostomian corner produced into bluntly acute angle, posterior margin with cardiac notch distinct. Rostrum longer than orbital hood (fig. 1), distinctly narrower, distally upturned; margins in dorsal view, straight. Orbitorostral process absent. Ocular hoods dorsally convex; in dorsal view, bluntly acute, separated from rostrum by deep adrostral sinus. Ocular process triangular, flanged posteriorly onto lower side of eye. Ocellary beak in lateral view not rodlike, broader at base. Stylocerite acute, with blunt tip; mesial margin concave; reaching midpoint of first segment of antennular peduncle. First antennular segment without ventromesial tooth, and with two basal ventral processes. Basicerite without spine on dorsomesial cor- ner, with longer ventrolateral spine, not reaching third segment of antennular peduncle. Scaphocerite blade absent, acute lateral spine robust, with lateral margin slightly concave, slightly surpassing basicerite spine, not reaching third segment of antennular peduncle; mesial projection at base of scaphocerite present. Third maxilliped (fig. 2) with distal circlet of spines on distal segment, without ventrodistal spine on antepenultimate segment. Remaining mouthparts as figured (fig. 2).

Major first pereopod (fig. 3) massive, fingers clearly shorter than half length of palm; fixed finger slightly shorter than dactyl. Palm of chela with distal superior margin protuberance, which is secondarily produced distally, directed slightly downward, toward dactyl.

Minor first pereopod (fig. 3) with palm clearly less than two times longer than high; fingers clearly shorter than palm; dactyl with flexor margin concave, bladelike, with 2 distinct distal teeth, subequal in length; transverse dorsal setal combs on dactyl, very conspicuous; fixed finger with flexor margin straight, bladelike, and 2 distinct teeth subequal in length.

Second pereopod (fig. 4) with carpus 5segmented, subequal in length to merus. Both fingers terminating in a narrow, curved tooth.

Third pereopod (fig. 4) slender; dactyl biunguiculate, with flexor unguis clearly thicker than extensor, mesial margin of flexor unguis strongly convex; propodus with row of 6 movable spines on flexor margin and one pair of distal movable spines flanking base of dactylus; carpus with distal movable spine on flexor margin; merus almost 4 times longer than wide, without movable spines on flexor margin; mesial lamella on coxa present. Fourth pereopod (fig. 4) similar to third, slightly weaker. Fifth pereopod (fig. 4) weaker than fourth; propodus with only 3 spines on flexor margin, and 4 transverse combs of stout setae on ventral face; carpus without distal spine.

First pleura (fig. 1) of male with posterior corner distinctly produced ventrally into small, anteriorly directed hook; second pleura of male broadly rounded; third to fifth pleura of male progressively acute, but not pointed. 


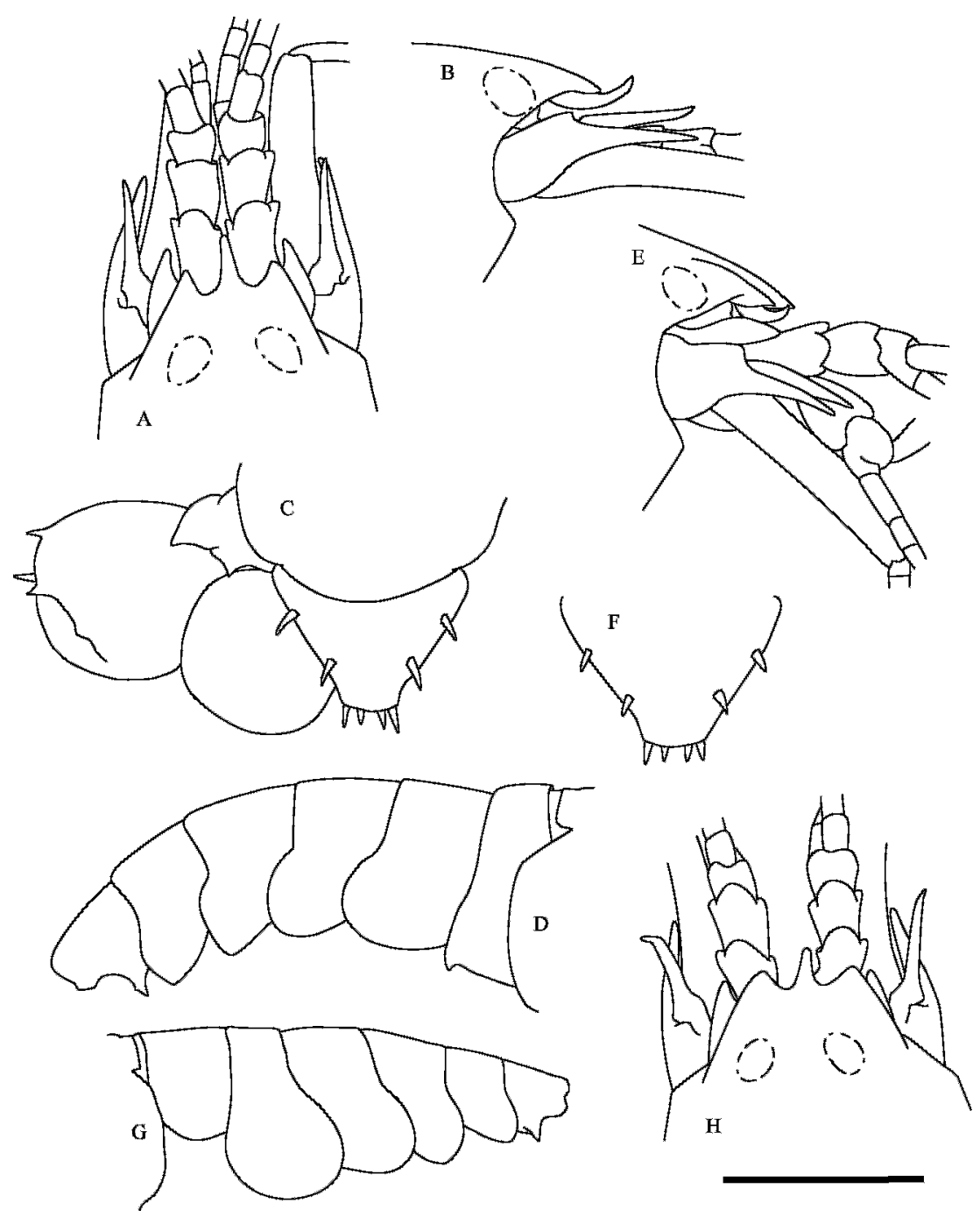

Fig. 1. Synalpheus carpenteri, new species. Holotype ơ $3.32 \mathrm{~mm}$ (USNM 1092295, VIMS04CBC4201) from Agelas clathrodes, Long Reef, Belize: A, anterior region of carapace and cephalic appendages, dorsal view; B, same, lateral view; C, telson and left uropods, dorsal view; D, abdomen, lateral view. Allotype $q$ 3.86 mm (USNM 1092296, VIMS 04CBC4202) from A. clathrodes, Long Reef, Belize: E, anterior region of carapace and cephalic appendages, lateral view; $\mathbf{F}$, telson, dorsal view; $\mathbf{G}$, abdomen, lateral view. $\delta 3.59 \mathrm{~mm}$ (VIMS 96CBC3304) from A. clathrodes, Carrie Bow Cay, Belize: $\mathbf{H}$, anterior region of carapace and cephalic appendages, dorsal view. Scale bar $=1 \mathrm{~mm}$ for A, B, C, E, F, H; $1.6 \mathrm{~mm}$ for D; $2.5 \mathrm{~mm}$ for G.

First pleopod (fig. 5) of male with 2 terminal setae on endopod; second pleopod of male with marginal setae on exopod originating in distal two-thirds; appendix interna present on second to fifth male pleopods. Second pleopod (fig. 5) of female with marginal setae on exopod originating in distal one-third; appendix interna present on second to fifth male pleopods.
Telson (fig. 1) length three-quarters width of proximal margin; marginal convex lobe present; posterior corners adjacent to spines obtuse. Anal flaps, perianal setae, and postanal setal brush absent. Uropods with a single fixed tooth on outer margin of exopod distinctly removed from the movable one, the latter slightly longer and more slender than adjacent inner fixed tooth. 

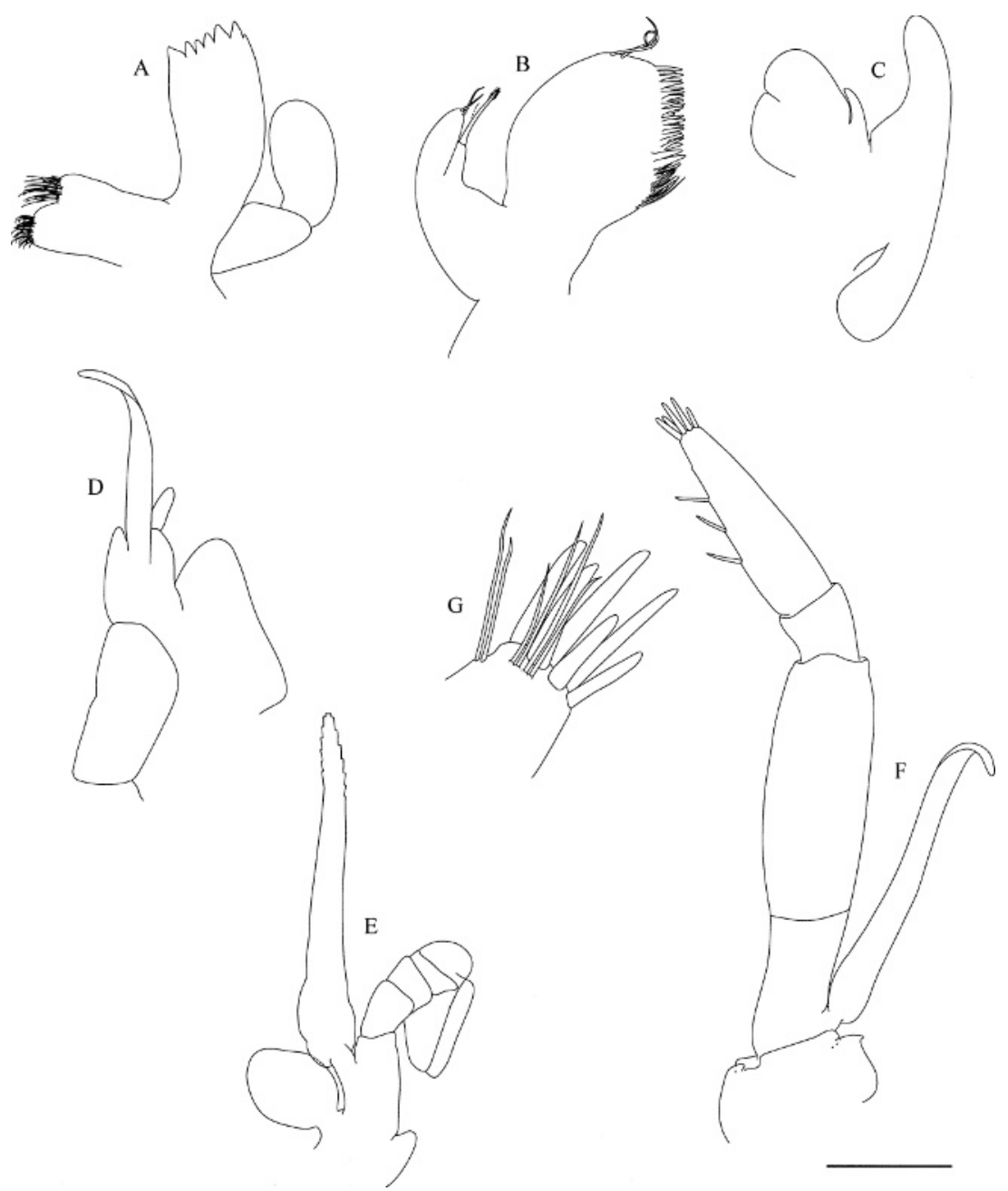

Fig. 2. Synalpheus carpenteri, new species. of $3.59 \mathrm{~mm}$ (USNM 1092298, VIMS 96CBC3304) from Agelas clathrodes, Carrie Bow Cay, Belize: A, mandible; B, first maxilla, in part; C, second maxilla; D, first maxilliped; E, second maxilliped; $\mathbf{F}$, third maxilliped; $\mathbf{G}$, same, detail of distal region. Scale bar $=1 \mathrm{~mm}$ for C, D, E, F; $0.5 \mathrm{~mm}$ for A; $0.25 \mathrm{~mm}$ for $\mathrm{B}, \mathrm{G}$.

COLOR IN LIFE: Faint to bright orange overall, color distinctly more intense in fingers and distal palm of major chela. Ovaries and developing embryos are brilliant orange.

EтYMOLOGY: We have named this species after Michael Carpenter, Caribbean Coral Reef Ecosystem program, National Museum of Natural History, Smithsonian Institution, without whose assistance and camaraderie over many years the work herein would have been impossible.

VARIATION: The shape of the telson varies from very broad and almost triangular to subquadrate; telson length/proximal margin width averages 0.77 (range $=0.67-0.88, N=$ $6)$. The lengths of the lateral spines of the scaphocerite and basicerite also vary. In most individuals, both spines are very short, extending to the midpoint of the second segment of antennular peduncle, while in some individuals both spines extend almost to the third segment of the antennular peduncle. There is also variation in the shape of the protuberance on the palm of the major chela. In some individuals, the protuberance appears rounded and is barely secondarily produced distally 


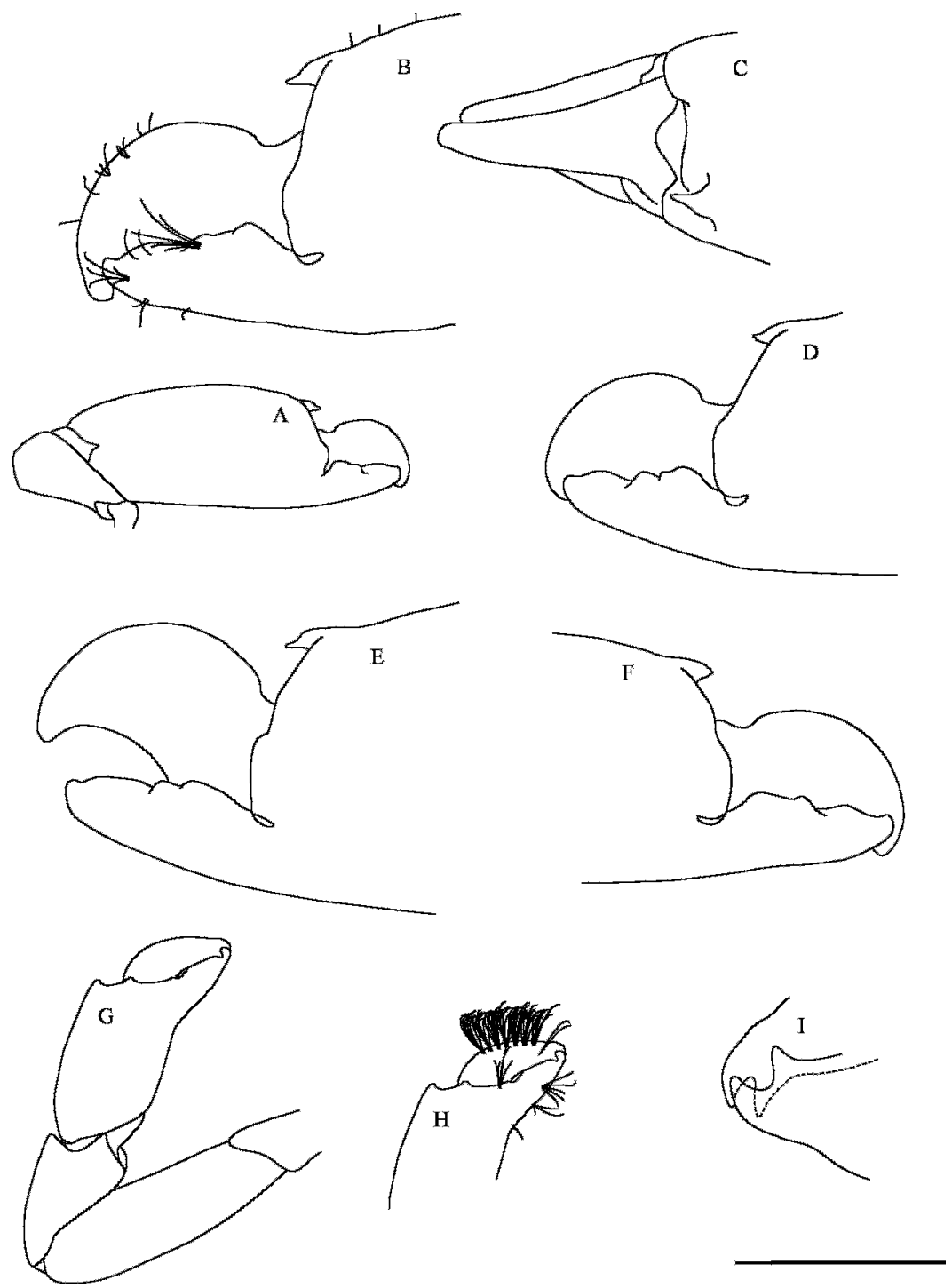

Fig. 3. Synalpheus carpenteri, new species. Holotype ô $3.32 \mathrm{~mm}$ (USNM 1092295, VIMS 04CBC4201) from Agelas clathrodes, Long Reef, Belize: A, chela of major first pereopod in lateral view; B, same, anterior region in lateral view; C, same, dorsal view. Allotype $93.86 \mathrm{~mm}$ (USNM 1092296, VIMS 04CBC4202) from $A$. clathrodes, Long Reef, Belize: D, anterior region of chela of major first pereopod in lateral view. $\hat{\delta}$ $3.59 \mathrm{~mm}$ (USNM 1092298, VIMS 96CBC3304) from A. clathrodes, Carrie Bow Cay, Belize: E, anterior region of chela of major first pereopod in lateral view. Paratype $\hat{\alpha} 2.74 \mathrm{~mm}$ (AMNH Crustacea xxx, VIMS 04CBC4305) from Agelas clathrodes, Long Reef, Belize: F, anterior region of chela of major first pereopod in lateral view; G, minor first pereopod, setae removed, lateral view; $\mathbf{H}$, same, anterior region, with setae; I, same, detail of distal tips of fingers, reverse view. Scale bar $=1 \mathrm{~mm}$ for B, C, D, E, F, G, H; $2.5 \mathrm{~mm}$ for A; $0.52 \mathrm{~mm}$ for I.

(figs. 3F, 6C, F), while in others the distal portion is strongly produced, becoming strongly acute distally (fig. 3B, D, E). Finally, the rostrum of the holotype (fig. 1A) is longer than is typically found in this species, although not entirely rare. The rostrum of most individuals (see figs. $1 \mathrm{H}, 6 \mathrm{~A}, \mathrm{~B}$ ) is subequal to or slightly longer than the orbital hoods. 


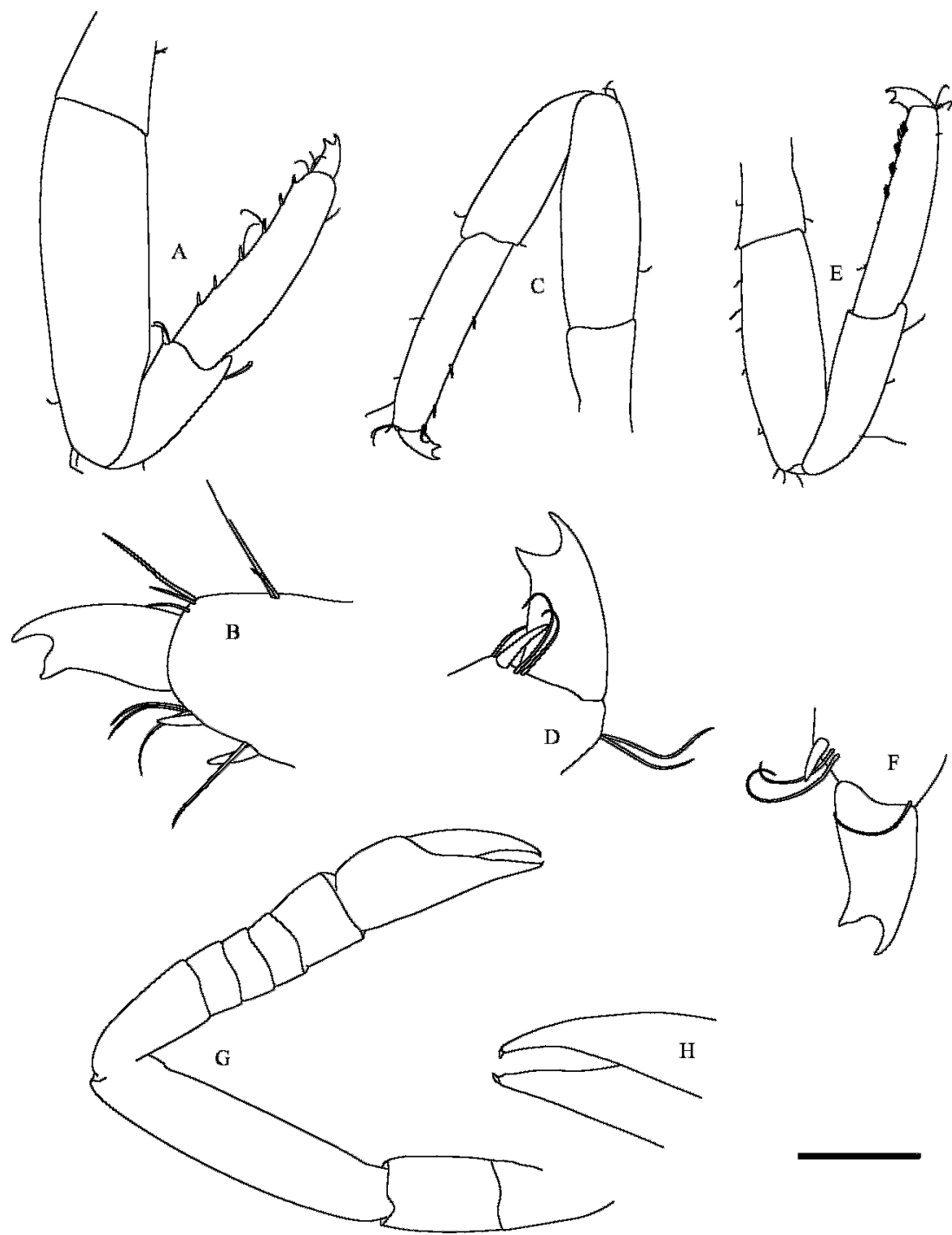

Fig. 4. Synalpheus carpenteri, new species. of $3.59 \mathrm{~mm}$ (USNM 1092298, VIMS 96CBC3304) from Agelas clathrodes, Carrie Bow Cay, Belize: A, third pereopod; B, same, detail of distal region; $\mathbf{C}$, fourth pereopod; D, same, detail of distal region; E, fifth pereopod; F, same, detail of distal region; $\mathbf{G}$, second pereopod; H, same, detail of distal region. Scale bar $=1 \mathrm{~mm}$ for A, C, E, G; $0.25 \mathrm{~mm}$ for B, D, F; $0.5 \mathrm{~mm}$ for $\mathrm{H}$.

Hosts AND ECOLOGY: Synalpheus carpenteri, n. sp. is a host specialist, found only in the canals of the common Caribbean sponges Agelas clathrodes and Agelas dispar. It is found in approximately equal sex ratios, and individual sponges can contain a single pair to several tens of shrimp. Synalpheus carpenteri is often found together in the host sponge with the closely related eusocial $S$. chacei and/or
Synalpheus agelas Pequegnat and Heard, 1979.

Distribution: Belize Barrier Reef; San Blas Islands, Panama; Exuma Islands, Bahamas.

Remarks: $S$. carpenteri is one member of a complex of closely related, morphologically similar Synalpheus species that includes $S$. brooksi, $S$. bousfieldi, and $S$. chacei. It is most similar morphologically to $S$. bousfieldi. The 


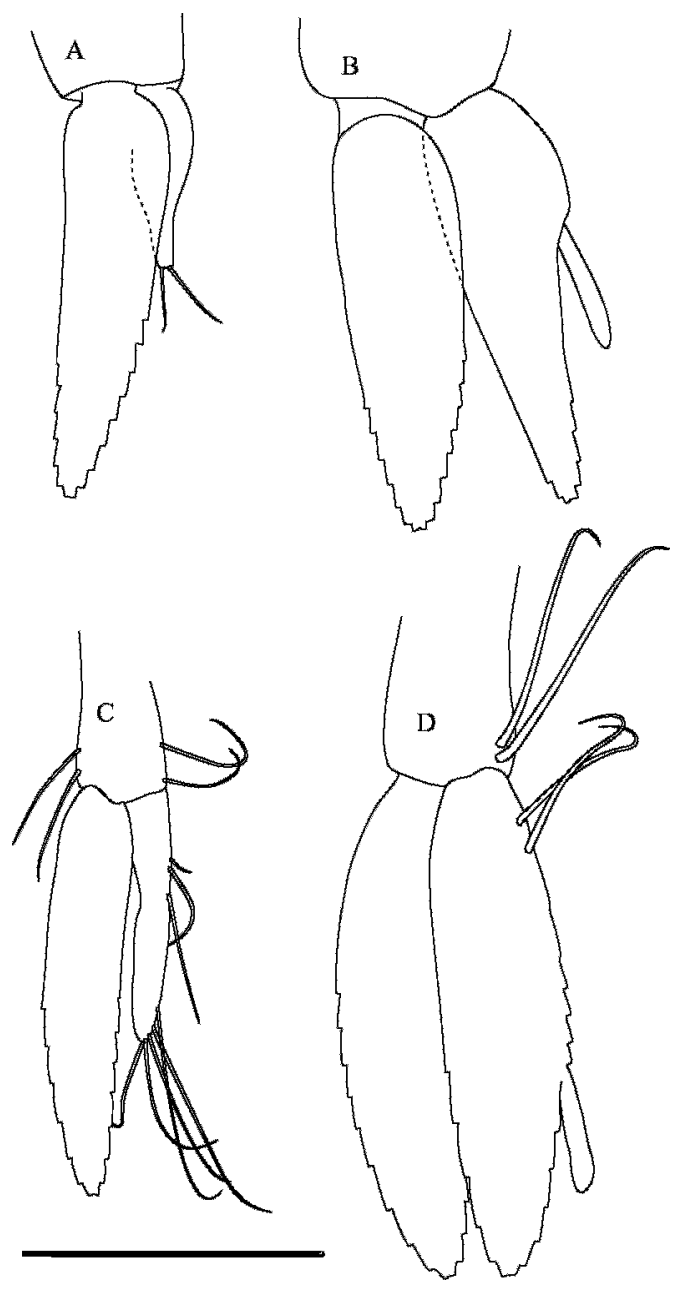

Fig. 5. Synalpheus carpenteri, new species. $\hat{\sigma}$ $3.59 \mathrm{~mm}$ (USNM 1092298, VIMS 96CBC3304) from Agelas clathrodes, Carrie Bow Cay, Belize: A, first pleopod; B, second pleopod. Paratype + $3.01 \mathrm{~mm}$ (AMNH Crustacea 18492, VIMS 04CBC4203) from $A$. clathrodes, Long Reef, Belize: C, first pleopod; D, second pleopod. Scale bar $=1 \mathrm{~mm}$.

most obvious identifying character of $S$. carpenteri is its color in life. No other member of the $S$. brooksi species complex shares the overall orange coloration of this species, or especially the brilliant orange of the ovaries and developing embryos. While there is variation in both the relative width of the telson and the relative lengths of the lateral spines of the basicerite and scaphocerite, there is little or no overlap in these characters with
S. bousfieldi. Telson length/proximal margin width ratios range from 0.67 to 0.88 in $S$. carpenteri $(N=6)$ and from 1.01 to 1.25 in $S$. bousfieldi $(N=13)$. Additionally, the lateral spines of the basicerite and scaphocerite barely, if ever, reach beyond the distal margin of the second segment of the antennular peduncle, while in all other members of the species complex, both spines typically reach a least beyond the midpoint of the third segment, and often past the distal margin of the third segment (see figs. 14 and 15, as well as Chace's [1972: 87, fig. 29] figure of the holotype and paratype of $S$. bousfieldi). It is likely that some of the specimens collected from Agelas dispar Duchassaing and Michelotti, 1864 examined by Dardeau (1984: fig. 10 ) and assigned to $S$. bousfieldi are actually $S$. carpenteri. We have occasionally found specimens that we consider to be $S$. bousfieldi inhabiting Agelas sp., but they are easily distinguishable from $S$. carpenteri in their overall dull color, narrow telson, and relatively long basicerite and scaphocerite lateral spines (personal obs.; fig. 17A-C). Specimens collected from Agelas clathrodes in the San Blas Islands of Panama (fig. 9) are provisionally assigned to $S$. carpenteri. While these specimens share the orange coloration and short lateral spines of the basicerite and scaphocerite, telson widths vary, and they are rarely as wide as in $S$. carpenteri individuals found in Belize or the Bahamas.

Synalpheus ruetzleri, new species figures 8-13

Synalpheus "bousfieldi blade", in Morrison et al., 2004, and in Macdonald et al., 2005.

Holotype: if (USNM 1092312, original VIMS 01CBC4502), Sand Bores, Belize, from canals of the blue cryptic sponge Hymeniacidon cf. caerulea Pulitzer-Finali, 1986. CL: $3.59 \mathrm{~mm}$.

Allotype: + (USNM 1092313, original VIMS 01CBC4501), Sand Bores, Belize, from canals of the same individual $H$. cf. caerulea as holotype. CL: $4.06 \mathrm{~mm}$.

PARATYPES: if (USNM 1092314, original VIMS 01CBC6101), Sand Bores, Belize, from canals of $H$. cf. caerulea. CL: $3.13 \mathrm{~mm}$. 우 (USNM 1092315, original VIMS 01CBC5601), 

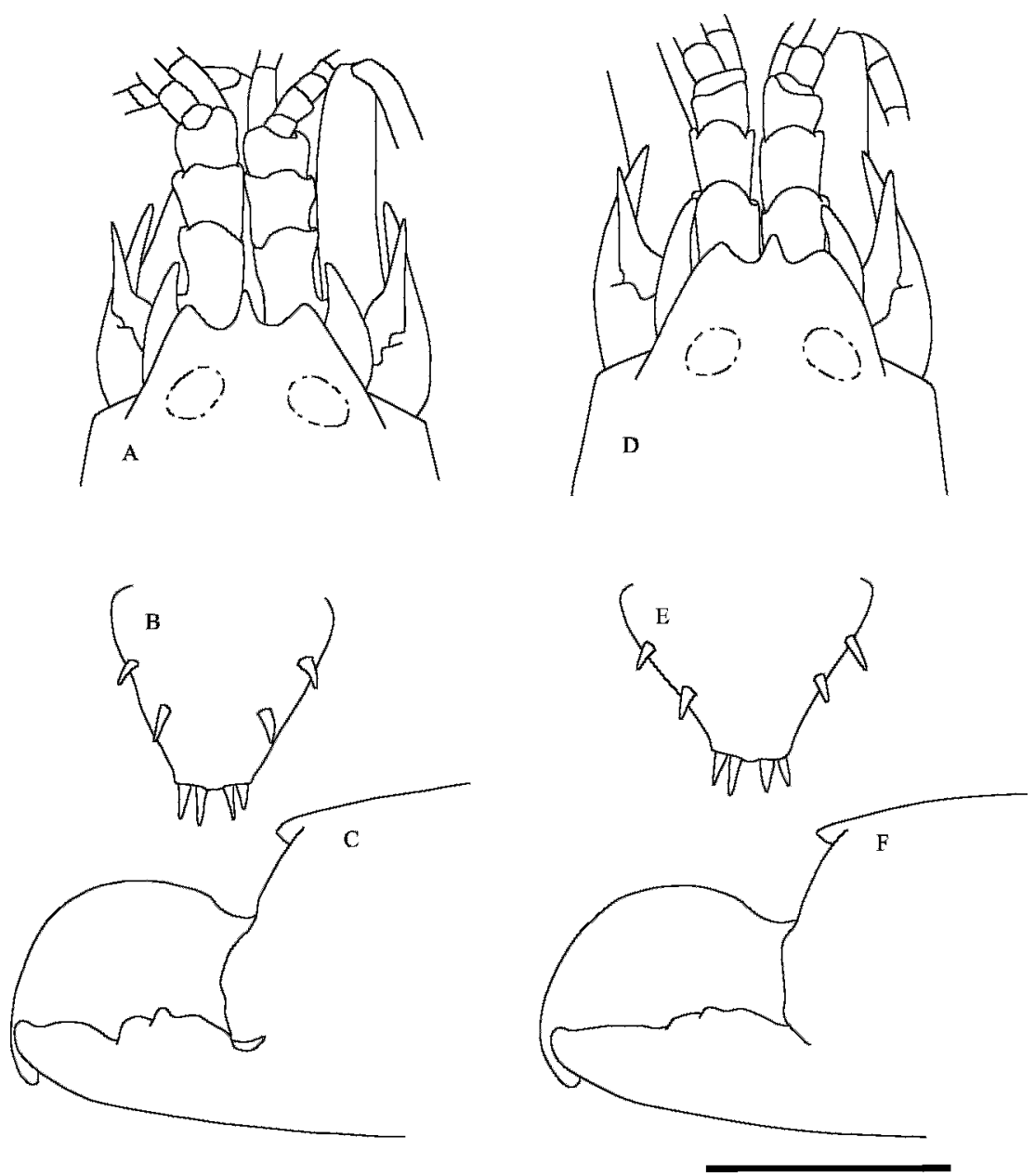

Fig. 6. Synalpheus carpenteri, new species. ㅇ $3.32 \mathrm{~mm}$ (USNM 1092302, VIMS 01LS1304) from Agelas clathrodes, G-spot, Exuma Islands, Bahamas: A, anterior region of carapace and cephalic appendages, dorsal view; B, telson, dorsal view; C, anterior region of chela of major first pereopod, lateral view. $\delta$ $3.36 \mathrm{~mm}$ (USNM 1092299, VIMS 01LS1301) from A. clathrodes, G-spot, Exuma Islands, Bahamas: $\mathbf{D}$, anterior region of carapace and cephalic appendages, dorsal view; $\mathbf{E}$, telson, dorsal view; $\mathbf{F}$, anterior region of chela of major first pereopod, lateral view. Scale bar $=1 \mathrm{~mm}$.

Sand Bores, Belize, from canals of $H$. cf. caerulea. CL: $3.51 \mathrm{~mm}$. \& (USNM 1092316, original VIMS 01CBC5602), Sand Bores, Belize, from canals of $H$. cf. caerulea. CL: $3.20 \mathrm{~mm}$. \& (AMNH Crustacea 18494, original VIMS 01CBC6301), Sand Bores, Belize, from canals of $H$. cf. caerulea. CL: $4.43 \mathrm{~mm}$. $\hat{\sigma}$ (AMNH Crustacea 18495, original VIMS 01CBC6302), Sand Bores, Belize, from canals of $H$. cf. caerulea. CL: $3.99 \mathrm{~mm}$.

Additional Specimens Examined: $q, \hat{\sigma}$ (VIMS 01CBC4601-02), Sand Bores, Belize, from canals of $H$. cf. caerulea. 오 , $\hat{o}$ (VIMS 93CBC1102-03), Blue Ground Range, Belize, from canals of $H$. cf. caerulea. ô (VIMS 01CBC1301), Blue Ground Range, Belize, from canals of $H$. cf. caerulea. \& (VIMS 93P3803), Wichubhuala Reef, San Blas Islands, Panama, from canals of $H$. cf. caerulea. o (USNM 1092317, original VIMS 91P4902), Guigalatupo Reef, San Blas Islands, Panama, from canals of an unidentified sponge. $\delta$ (VIMS 91P4101), Porvenir Reef, San Blas Islands, Panama, from canals of an unidenti- 

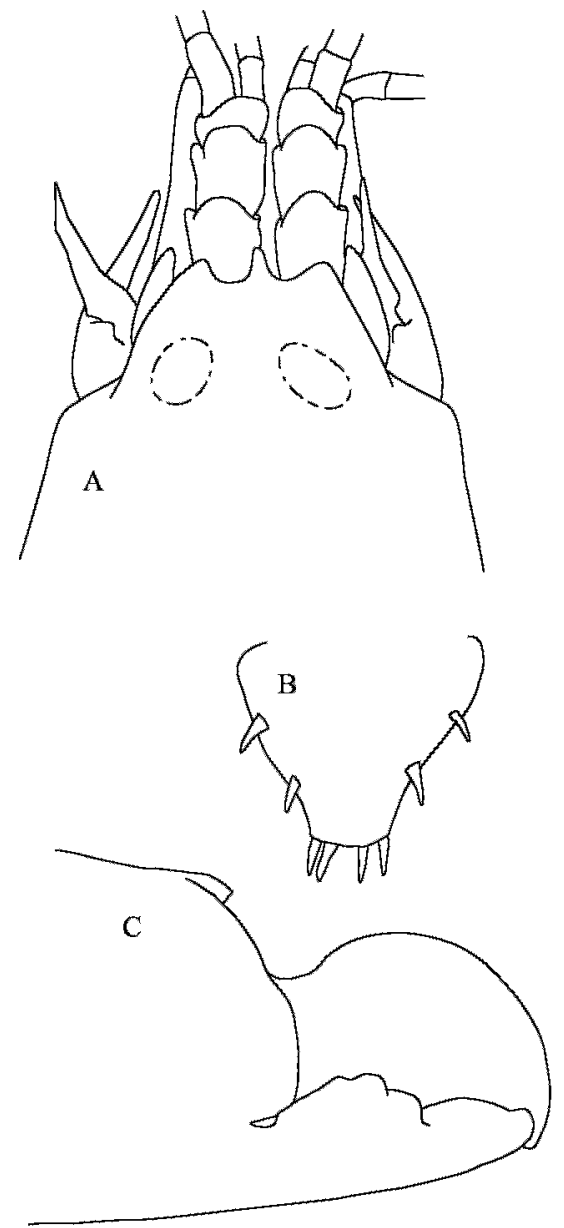
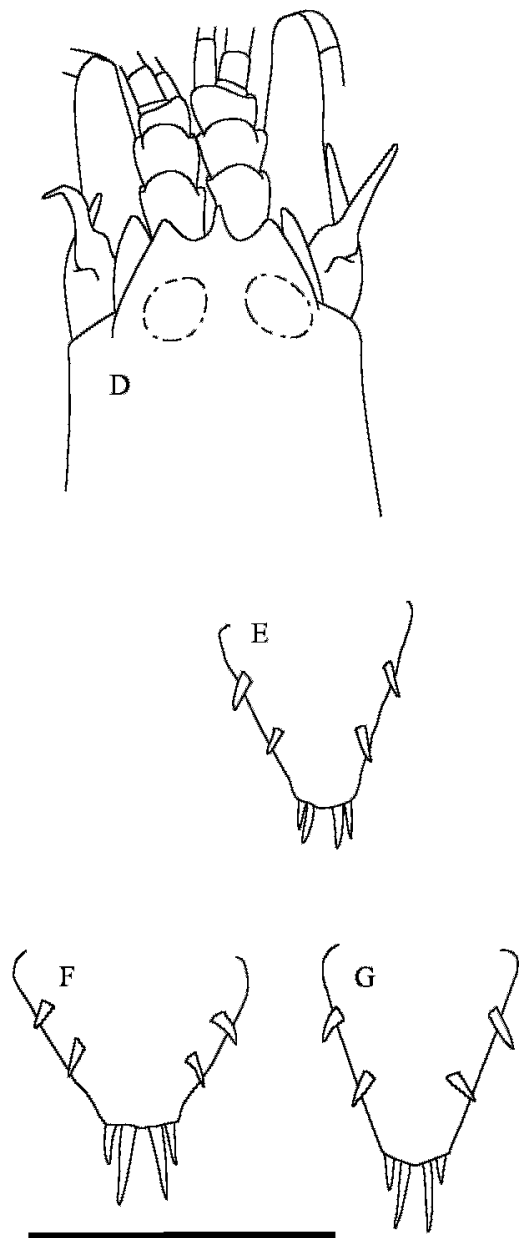

Fig. 7. Synalpheus cf. carpenteri, new species. ㅇ $3.32 \mathrm{~mm}$ (USNM 1092309, VIMS 92P6103) from Agelas clathrodes, San Blas Island, Panama: A, anterior region of carapace and cephalic appendages, dorsal view; $\mathbf{B}$, telson, dorsal view; $\mathbf{C}$, anterior region of chela of major first pereopod, lateral view. $\hat{\delta} 2.14 \mathrm{~mm}$ (USNM 1092308, VIMS 92P6102) from A. clathrodes, San Blas Island, Panama: D, anterior region of carapace and cephalic appendages, dorsal view; E, telson, dorsal view. ㅇ $2.49 \mathrm{~mm}$ (USNM 1092311, VIMS 92P6904): F, telson, dorsal view. o $2.26 \mathrm{~mm}$ (USNM 1092310, VIMS 92P6903) from A. clathrodes, Mamitupo Reef, San Blas Islands, Panama: G, telson, dorsal view. Scale bar $=1 \mathrm{~mm}$.

fied orange tube sponge. $\delta$ (VIMS 91P0703), Ulagsukun Reef, San Blas Islands, Panama, from canals of an unidentified sponge.

DESCRIPTION: Body form subcylindrical; carapace smooth, sparsely setose, with pterygostomian corner produced into bluntly acute angle, and posterior margin with cardiac notch distinct. Rostrum (fig. 8) longer than orbital teeth, and slightly narrower, distally upturned; margins in dorsal view, straight. Orbitorostral process absent. Ocular hoods dorsally convex; in dorsal view, bluntly acute, separated from rostrum by deep adrostral sinus. Ocular process triangular, flanged posteriorly onto lower side of eye. Ocellary beak in lateral view not rodlike, broader at base. Stylocerite acute, with blunt tip; mesial margin concave, surpassing midpoint of first segment of antennular peduncle; this segment without ventromesial tooth, with two basal ventral processes. Basicerite without spine on dorsomesial corner, with longer lateral spine, 

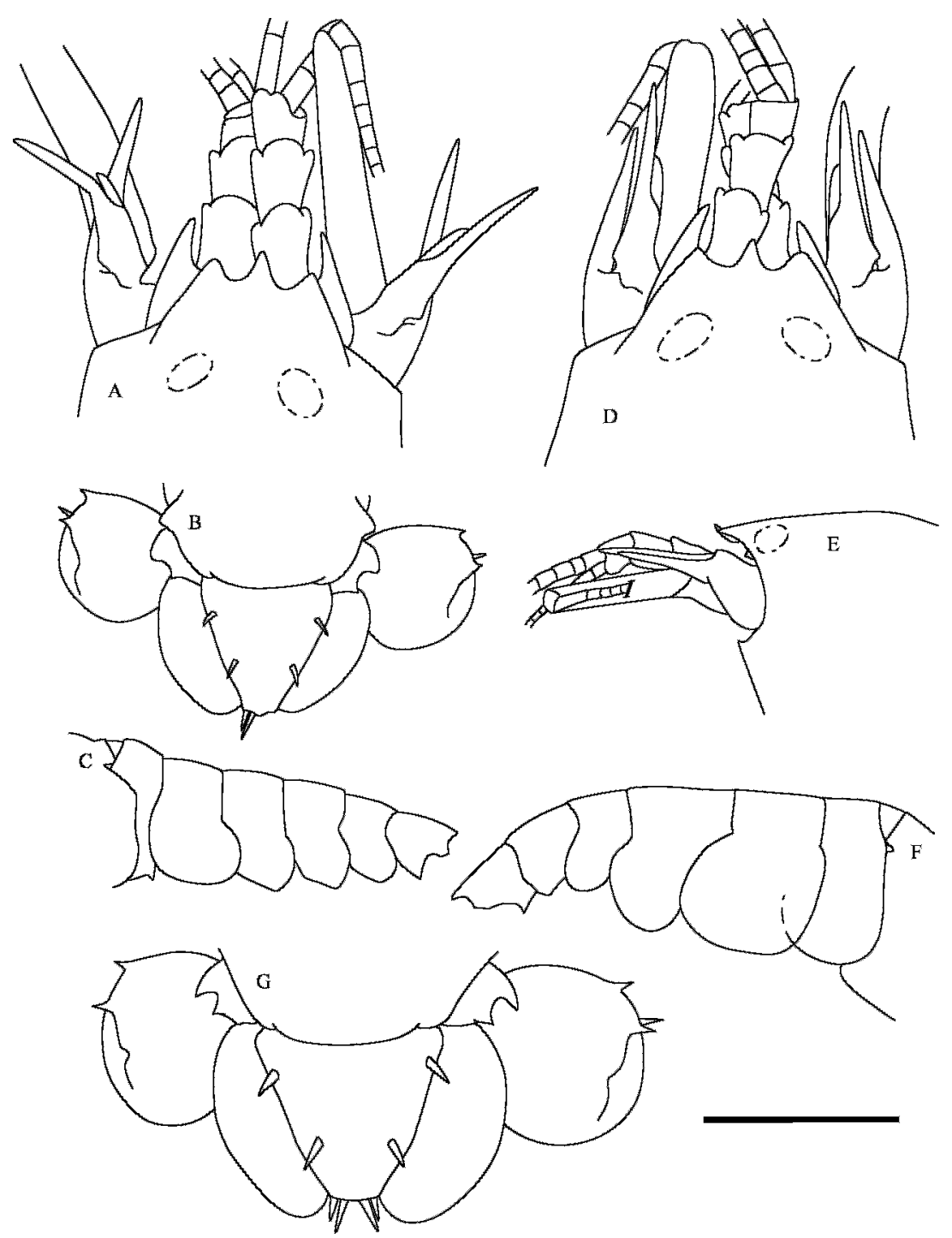

Fig. 8. Synalpheus ruetzleri, new species. Holotype \& $3.59 \mathrm{~mm}$ (USNM 1092312, VIMS 01CBC4502) from Hymeniacidon cf. caerulea, Sand Bores, Belize: A, anterior region of carapace and cephalic appendages, dorsal view; B, telson and uropods, dorsal view; $\mathbf{C}$, abdomen, lateral view. Allotype $+4.06 \mathrm{~mm}$ (USNM 1092313, VIMS 01CBC4501) from H. cf. caerulea, Sand Bores, Belize: D, anterior region of carapace and cephalic appendages, dorsal view; E, same, lateral view; F, abdomen, lateral view. Paratype $\delta 3.13 \mathrm{~mm}$ (USNM 1092314, VIMS 01CBC6101) from $H$. cf. caerulea, Sand Bores, Belize: G, telson and uropods, dorsal view. Scale bar $=1 \mathrm{~mm}$ for A, B, C, D, G; $2.5 \mathrm{~mm}$ for E, F.

reaching distal half of third segment of antennular peduncle. Scaphocerite with welldeveloped blade, reaching to almost half the length of lateral spine; acute lateral spine robust, with lateral margin slightly concave, slightly surpassing basicerite spine, slightly overreaching antennular peduncle; mesial pro- jection at base of scaphocerite present. Third maxilliped (fig. 9) with distal circlet of spines on distal segment, without ventrodistal spine on antepenultimate segment. Remaining mouthparts as figured (fig. 9).

Major first pereopod (fig. 10) massive, fingers clearly shorter than half length of palm; 

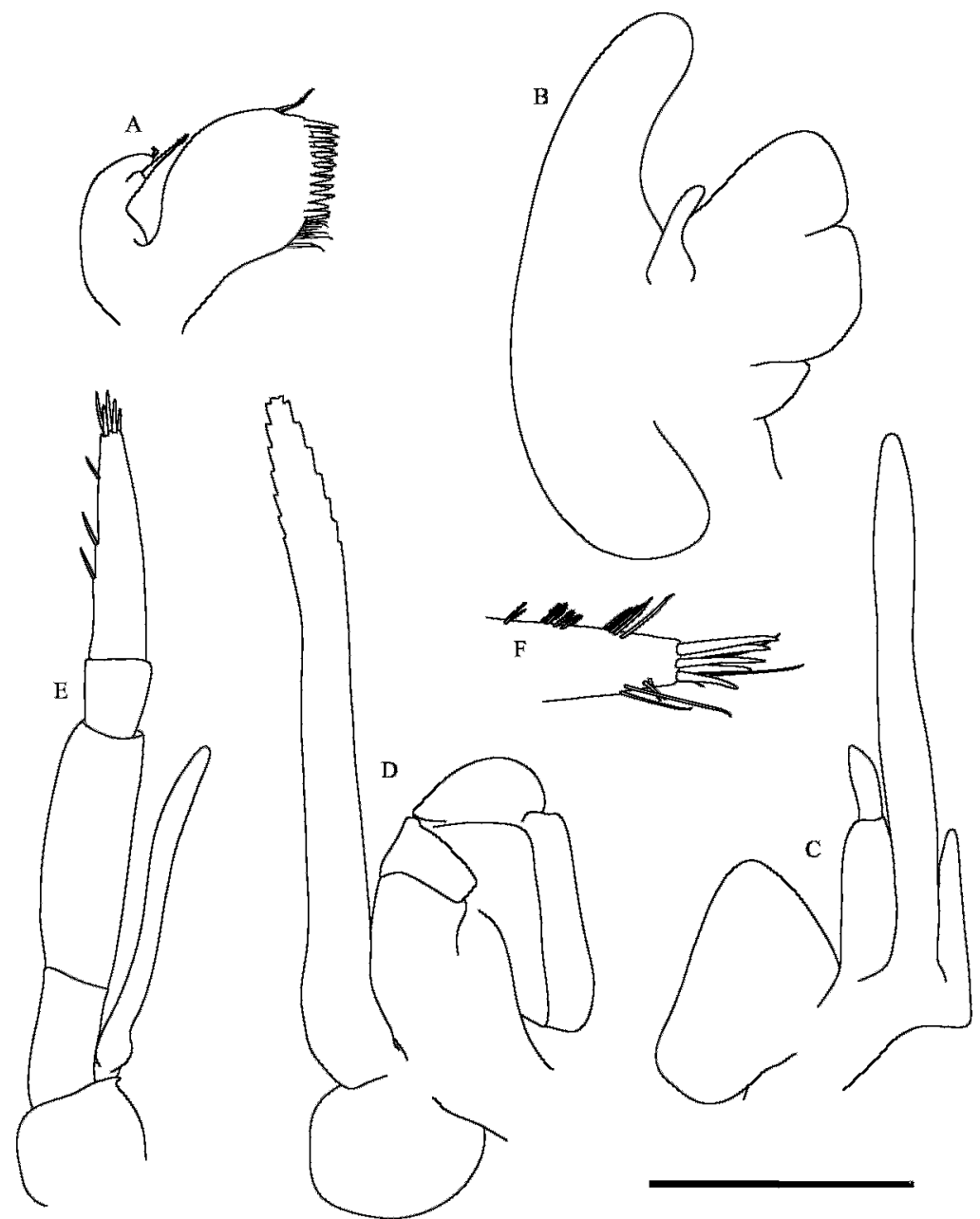

Fig. 9. Synalpheus ruetzleri, new species. Paratype of $3.13 \mathrm{~mm}$ (USNM 1092314, VIMS 01CBC6101) from Hymeniacidon cf. caerulea, Sand Bores, Belize: A, first maxilla, in part; B, second maxilla; $\mathbf{C}$, first maxilliped; D, second maxilliped; $\mathbf{E}$, third maxilliped; F, same, detail of distal region. Scale bar $=1 \mathrm{~mm}$ for $\mathrm{A}, \mathrm{B}, \mathrm{C}, \mathrm{D} ; 0.5 \mathrm{~mm}$ for $\mathrm{E} ; 0.25 \mathrm{~mm}$ for $\mathrm{F}$.

fixed finger slightly shorter than dactyl. Palm of chela with distal superior margin protuberance, which is secondarily produced distally, slightly curved downward, toward dactyl.

Minor first pereopod (fig. 10) with palm clearly less than two times longer than high; fingers clearly shorter than palm; dactyl with flexor margin straight, bladelike, with 2 distinct distal teeth, subequal in length, and parallel to dactyl axis; transverse dorsal setal combs on dactyl, very conspicuous; fixed finger with flexor margin straight, bladelike, and 2 distinct teeth subequal in length.
Second pereopod (fig. 11) with carpus 5segmented, subequal to merus. Both fingers terminating in narrow, curved tooth.

Third pereopod (fig. 11) slender; dactyl biunguiculate, with flexor unguis clearly thicker than extensor; propodus with row of 7 mobile spines on flexor margin and one pair of distal mobile spines flanking base of dactylus; carpus with distal mobile spine on flexor margin; merus almost 4 times longer than wide, without movable spines on flexor margin; mesial lamella on coxa present. Fourth pereopod (fig. 11) similar to third, slightly weaker. 


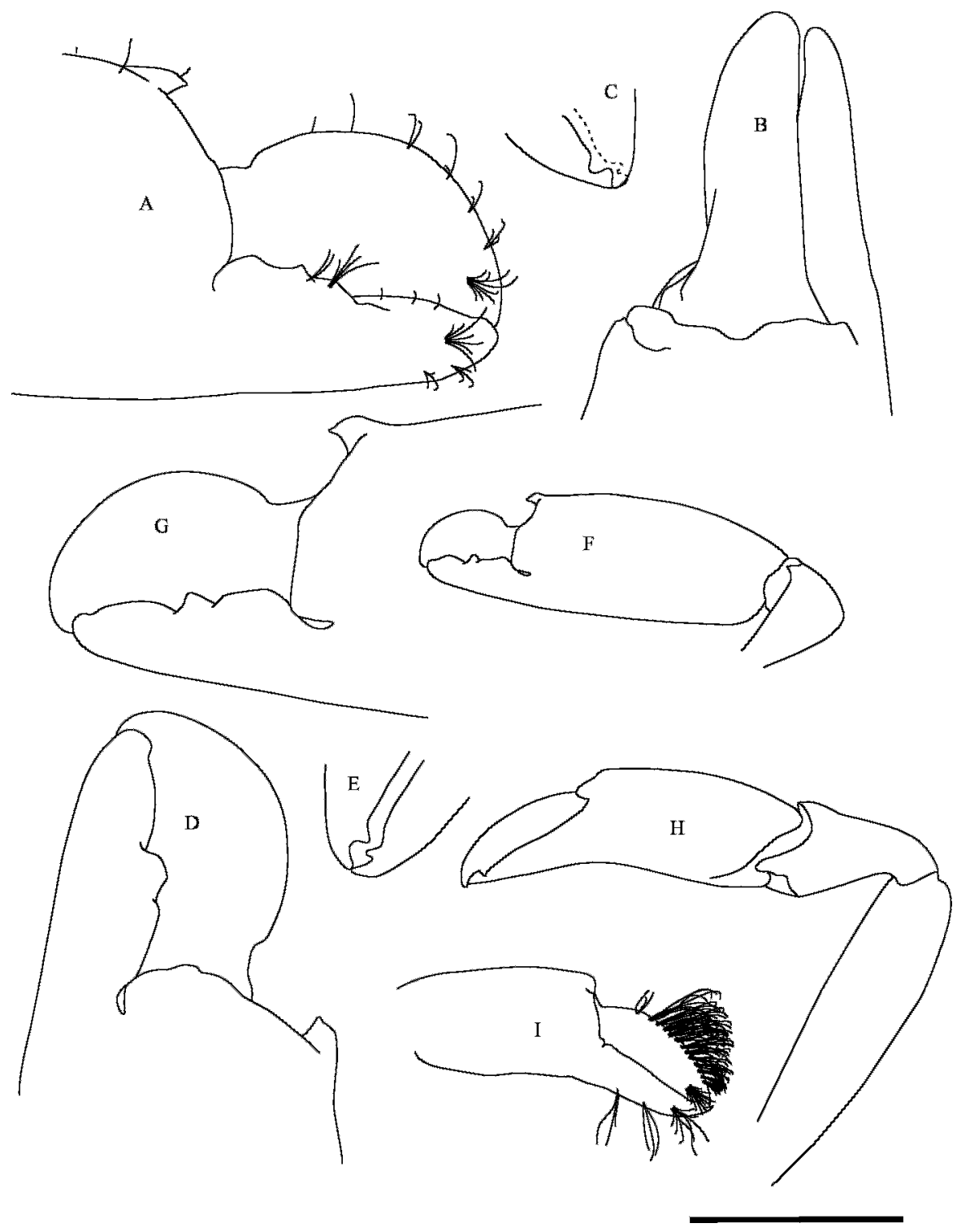

Fig. 10. Synalpheus ruetzleri, new species. Holotype ô $3.59 \mathrm{~mm}$ (USNM 1092312, VIMS 01CBC4502) from Hymeniacidon cf. caerulea, Sand Bores, Belize: A, anterior region of chela of major first pereopod, lateral view; B, same, dorsal view; $\mathbf{C}$, detail of distal region of chela of minor first pereopod. Allotype $q$ $4.06 \mathrm{~mm}$ (USNM 1092313, VIMS 01CBC4501) from $H$. cf. caerulea, Sand Bores, Belize: D, anterior region of chela of major first pereopod, lateral view; E, detail of distal region of chela of minor first pereopod. Paratype \$ 3.13 mm (USNM 1092314, VIMS 01CBC6101) from H. cf. caerulea, Sand Bores, Belize: F, chela of major first pereopod, lateral view; $\mathbf{G}$, same, anterior region, lateral view; $\mathbf{H}$, chela of minor first pereopod, setae removed; I, same, alternate view with setae. Scale bar $=1 \mathrm{~mm}$ for A, B, C, D, E, F, H, I; $2.5 \mathrm{~mm}$ for G.

Fifth pereopod (fig. 11) weaker than fourth; propodus with only 2 spines on flexor margin, 5 transverse combs of stout setae on ventral face; carpus without distal spine.
First pleura (fig. 8) of male with posterior corner distinctly produced ventrally into small, anteriorly directed hook; second pleura of male broadly rounded; third to fifth 


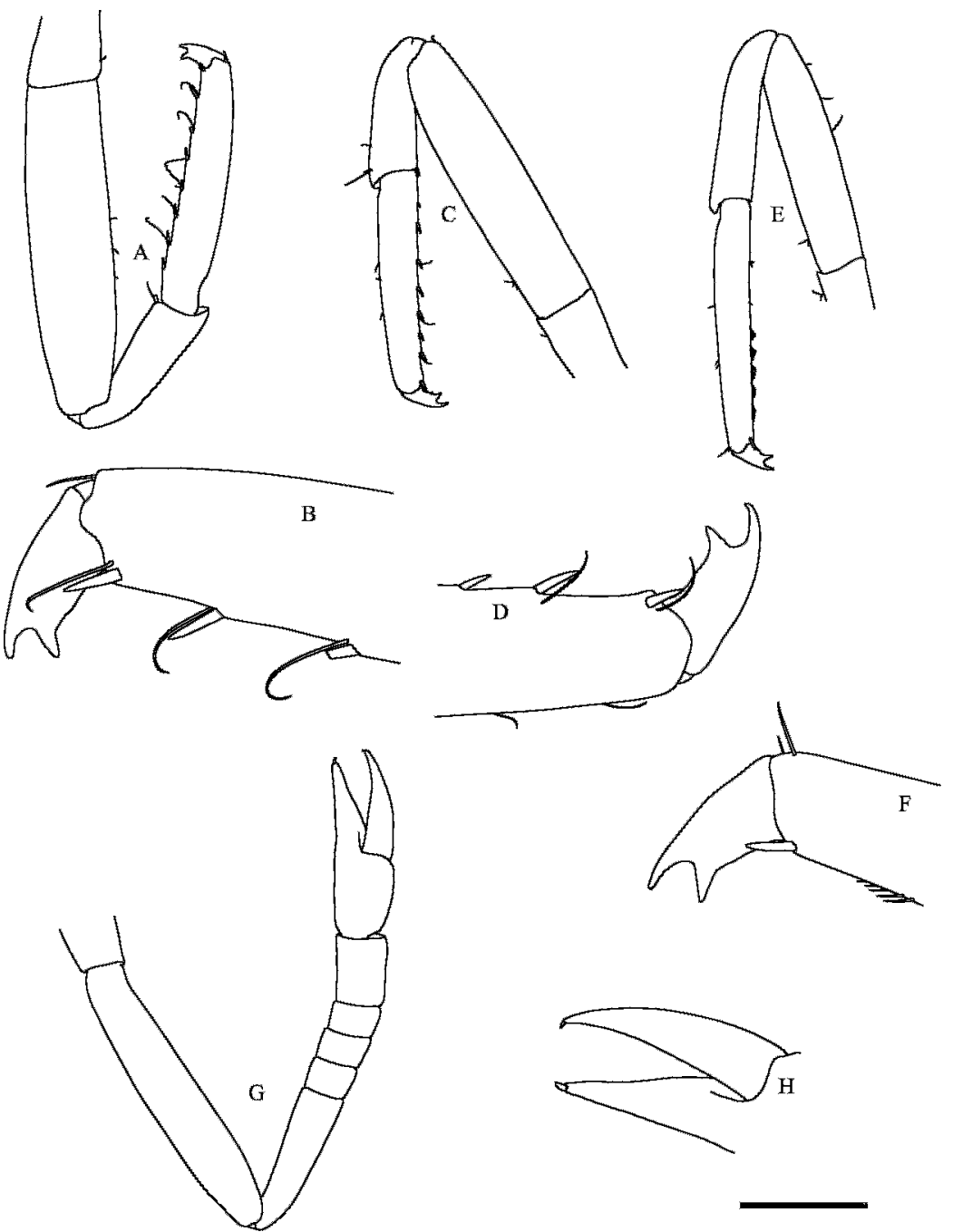

Fig. 11. Synalpheus ruetzleri, new species. Paratype के $3.13 \mathrm{~mm}$ (USNM 1092314, VIMS 01CBC6101) from Hymeniacidon cf. caerulea, Sand Bores, Belize: A, third pereopod; B, same, detail of distal region; $\mathbf{C}$, fourth pereopod; D, same, detail of distal region; $\mathbf{E}$, fifth pereopod; $\mathbf{F}$, same, detail of distal region; G, second pereopod; $\mathbf{H}$, same, detail of distal region. Scale bar $=1 \mathrm{~mm}$ for A, C, E, G; $0.25 \mathrm{~mm}$ for B, D, F; $0.5 \mathrm{~mm}$ for $\mathrm{H}$.

pleura of male progressively acute, but not pointed.

First pleopod (fig. 12) of male with 2 terminal setae on endopod; second pleopod of male with marginal setae on exopod originating in distal half; appendix interna present on second to fifth male pleopods. Second pleopod (fig. 12) of female with marginal setae on exopod originating in distal half; appendix interna present on second to fifth male pleopods.
Telson (fig. 8) with marginal convex lobe present; posterior corners adjacent to spines obtuse. Anal flaps, perianal setae, postanal setal brush all absent. Uropods with a single fixed tooth on outer margin of exopod distinctly removed from the mobile one, which is longer and more slender than adjacent inner fixed tooth.

COlOR IN Life: Nondescript, translucent with dull gold tinge to thickened parts of cuticle; distal palm and fingers of major chela 

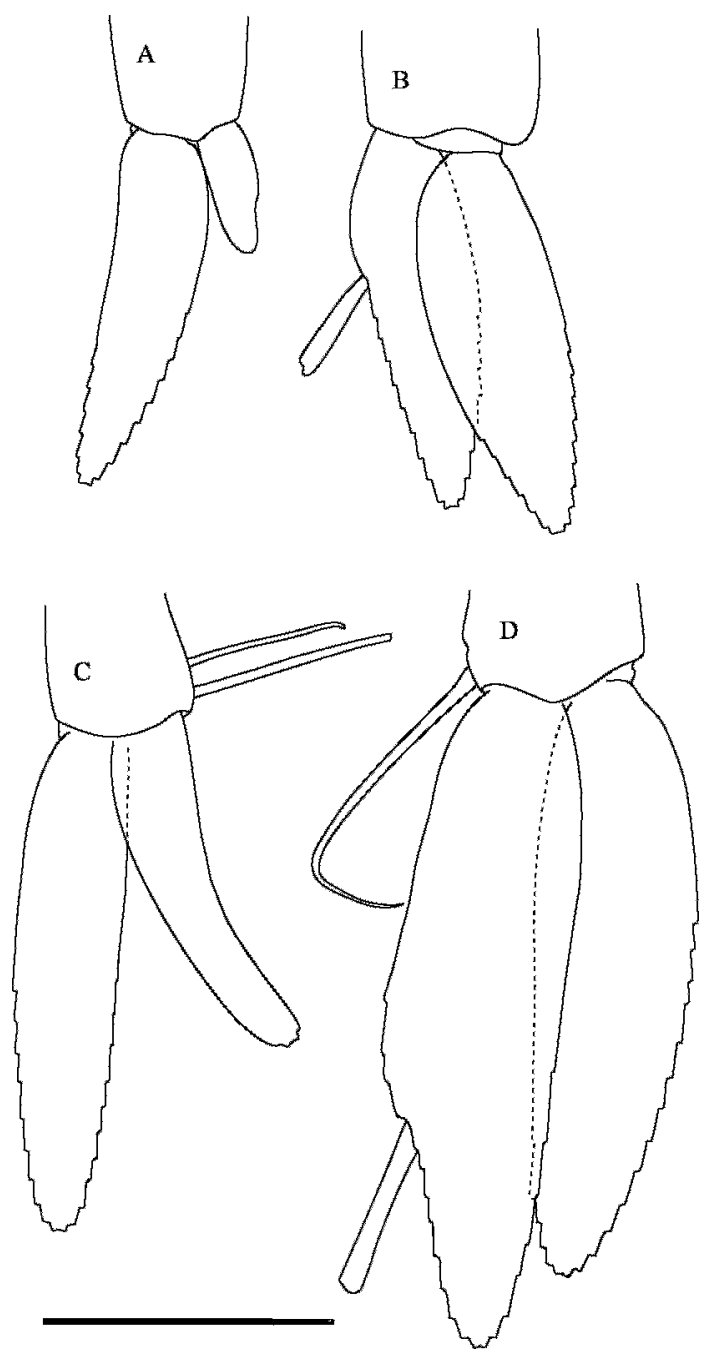

Fig. 12. Synalpheus ruetzleri, new species. Paratype o $3.13 \mathrm{~mm}$ (USNM 1092314, VIMS 01CBC6101) from Hymeniacidon cf. caerulea, Sand Bores, Belize: A, first pleopod; B, second pleopod. Allotype ㅇ $4.06 \mathrm{~mm}$ (USNM 1092313, VIMS 01CBC4501) from $H$. cf. caerulea, Sand Bores, Belize: $\mathbf{C}$, first pleopod; D, second pleopod. Scale bar $=1 \mathrm{~mm}$.

brownish; ovaries and eggs olive green to chestnut brown.

ETYMOLOGY: This species is named in honor of Dr. Klaus Ruetzler, National Museum of Natural History, Smithsonian Institution. Dr. Ruetzler has been invaluable in facilitating 15 years of research at Carrie
Bow Cay, Belize, and specifically in his assistance with sponge identification.

VARIATION: The length of the scaphocerite blade varies in this species, ranging from onethird to just over half the length of the lateral spine of the scaphocerite. The relative lengths of the distal teeth on the fingers of the minor first pereopod vary as well. In some specimens the distal tooth is larger than the proximal tooth (fig. $10 \mathrm{H}$ ), while in others the teeth are subequal in length (fig. 10C).

Hosts AND ECOlOGY: In Belize, Synalpheus ruetzleri appears to be a specialist on the cryptic midnight-blue sponge Hymeniacidon cf. caerulea. It is almost invariably found as a single heterosexual pair within a sponge. In Panama it is predominantly found in $H$. cf. caerulea, but it was also collected from several other unidentified sponges.

Distribution: Belize Barrier Reef, San Blas Islands, Panama.

REMARKs: Synalpheus ruetzleri is another member of the complex of closely related, morphologically similar Synalpheus shrimp that include $S$. brooksi, $S$. bousfieldi, and $S$. chacei. Like $S$. carpenteri, it is most similar morphologically to $S$. bousfieldi. Unlike several of the other species within this complex, $S$. ruetzleri is difficult to distinguish by color. $S$. ruetzleri is generally very similar in overall color pattern to $S$. bousfieldi, which also can inhabit the same species of sponge, $H$. cf. caerulea. This makes field identification practically impossible without a microscope. However, the presence of a blade is a remarkably consistent character differentiating these two species. While both $S$. ruetzleri and $S$. bousfieldi can inhabit the same host species, 14 years of sampling have never produced a cohabiting bladed and unbladed pair, suggesting strong assortative mating.

Synalpheus bousfieldi Chace, 1972 figures 14-15

Synalpheus bousfieldi Chace, 1972 (in part): 86, figs. 29, 30; Dardeau 1984 (in part): 19-25, figs. 7-10. NEW SYNONYMY.

Holotype: + (USNM 135369), Bahía del Espírutu Santo.

Paratypes: o , of (USNM 135370), Bahía del Espírutu Santo. 


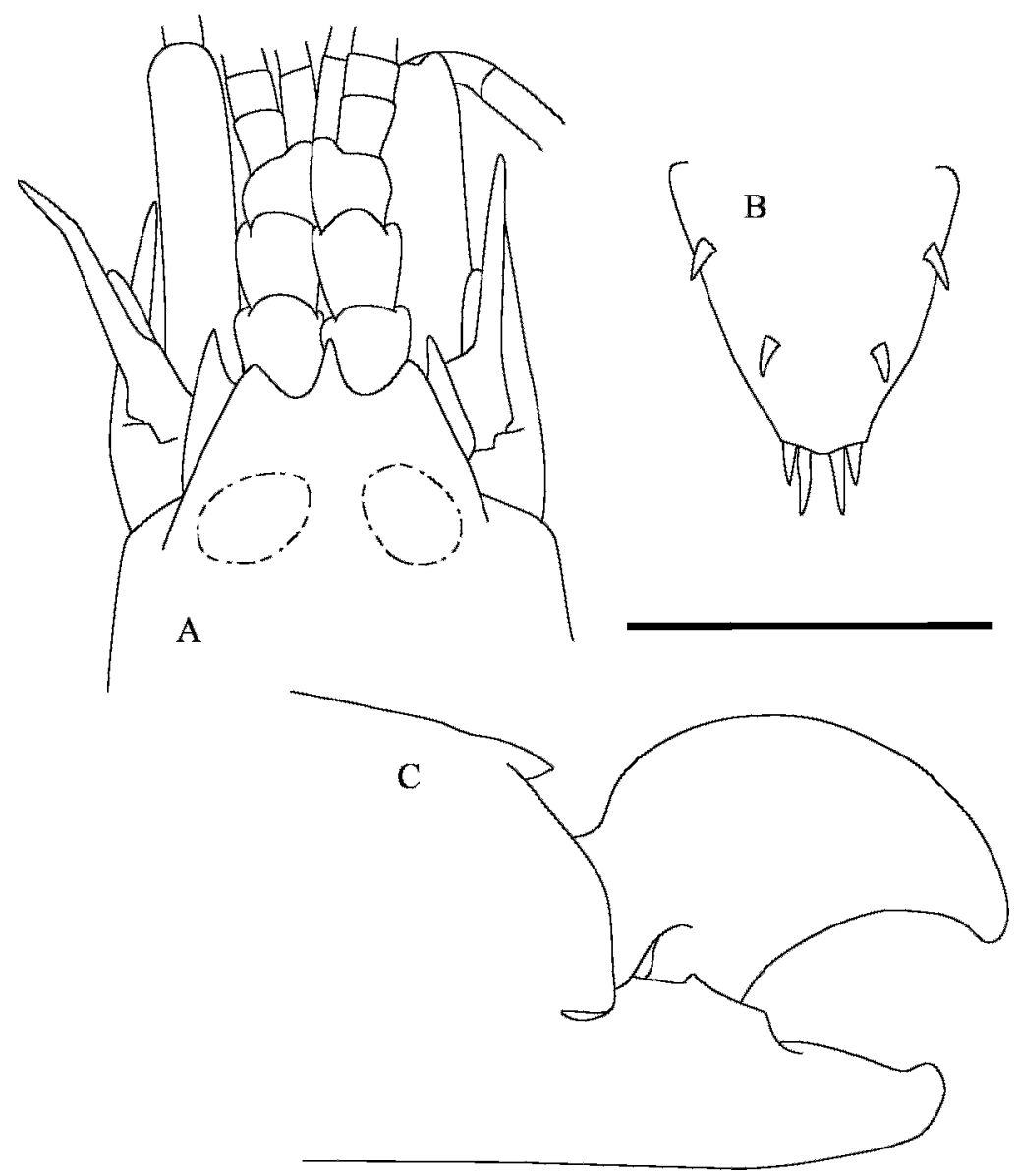

Fig. 13. Synalpheus ruetzleri, new species. of $2.70 \mathrm{~mm}$ (USNM 1092317, VIMS 91P4902) from unidentified sponge, Guigalatupo Reef, San Blas Islands, Panama: A, anterior region of carapace and cephalic appendages, dorsal view; B, telson, dorsal view; $\mathbf{C}$, anterior region of chela of major first pereopod, lateral view. Scale bar $=1 \mathrm{~mm}$.

Additional Specimens Examined: $q, 2 \hat{\delta}$ (VIMS 98CBC1001-03), Sand Bores, Belize, from the canals of Hymeniacidon cf. caerulea. ㅇ, of (VIMS 98CBC3304-05), Carrie Bow Cay, Belize, from the canals of Agelas clathrodes. + , of (VIMS 01LS1601-02), G-spot, Exuma Islands, Bahamas, from the canals of Hyatella sp. $\delta$ (VIMS 01CBC6003), Sand Bores, Belize, from the canals of $H$. cf. caerulea. + , of (VIMS 01CBC6201-02), Sand Bores, Belize, from the canals of $H$. cf. caerulea. o (VIMS 01CBC4502), Sand Bores, Belize, from the canals of $H$. cf. caerulea. 9 o, 6 o (VIMS 03CBC1801-02, 1811-15, 1817-21, 1825-27), Carrie Bow Cay, Belize, from the canals of Hyatella intestinalis Lamark, 1814. + , $\hat{\sigma}$
(VIMS 03CBC2001-02), Carrie Bow Cay, Belize, from the canals of $H$. cf. caerulea. + , of (VIMS 03CBC2401-02), Long Reef, Belize, from the canals of $H$. intestinalis. $2 \delta$ (VIMS 03CBC2701-02), Sand Bores, Belize, from the canals of $H$. cf. caerulea. 2 o (VIMS 04CBC0404-05), Curlew Reef, Belize, from the canals of $H$. intestinalis.

COLOR IN LIFE: Nondescript; translucent with dull gold tinge to thickened parts of cuticle; distal palm and fingers of major chela brownish; ovaries and developing embryos olive green to chestnut brown.

Hosts And ECOLOGY: Synalpheus bousfieldi most commonly inhabits Hyatella intestinalis and the midnight blue sponge Hymeniacidon 


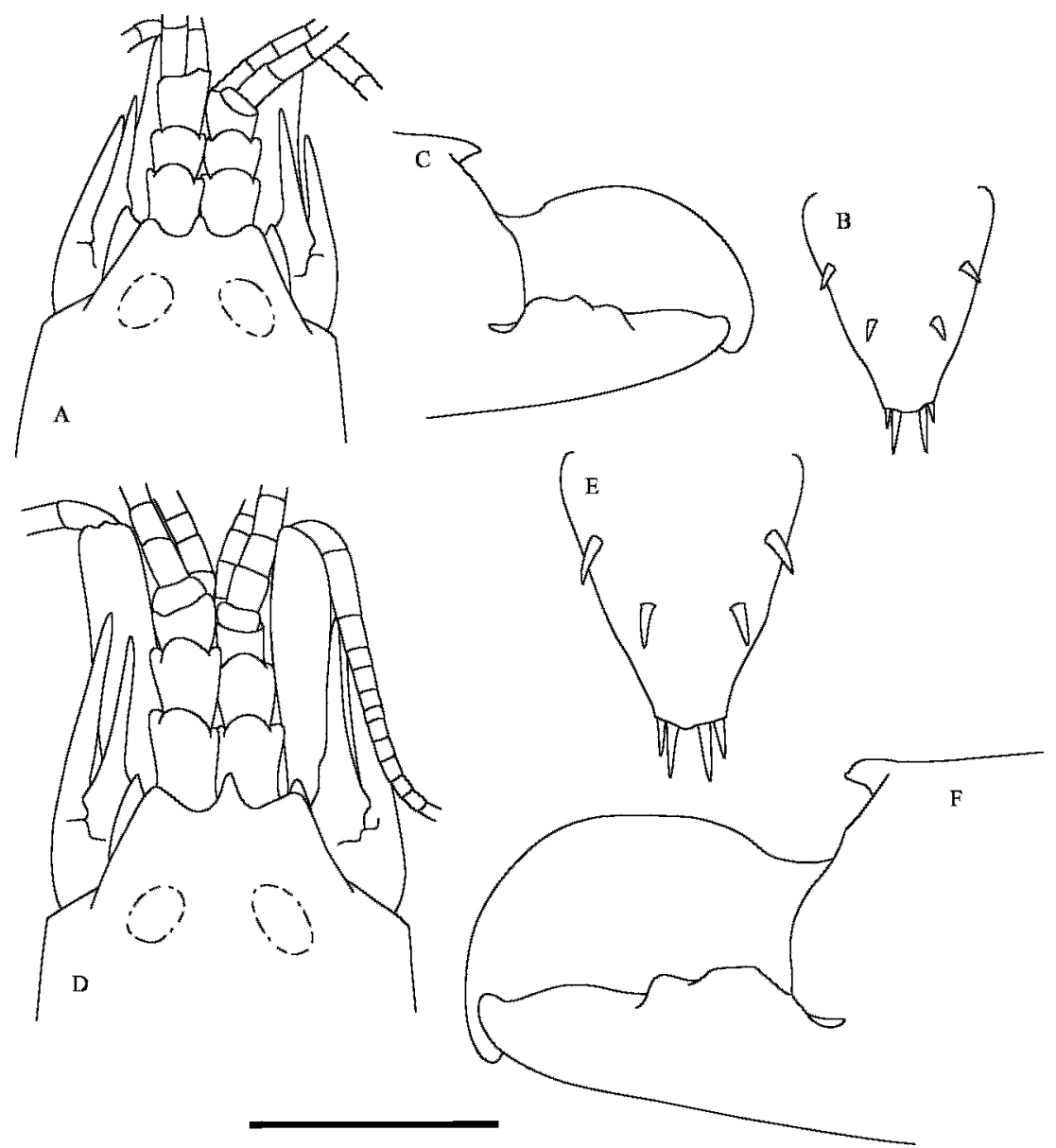

Fig. 14. Synalpheus bousfieldi. 2.86 mm (VIMS 98CBC3304) from Agelas clathrodes, Carrie Bow Cay, Belize: A, anterior region of carapace and cephalic appendages, dorsal view; B, telson, dorsal view; C, anterior region of chela of major first pereopod, lateral view. \& $3.47 \mathrm{~mm}$ (VIMS 98CBC1003) from Hymeniacidon cf. caerulea, Sand Bores, Belize: D, anterior region of carapace and cephalic appendages, dorsal view; $\mathbf{E}$, telson, dorsal view; $\mathbf{F}$, anterior region of chela of major first pereopod, lateral view. Scale bar $=1 \mathrm{~mm}$.

cf. caerulea, but it has been found uncommonly in a wide variety of other sponges (personal obs.; Macdonald et al., 2005). It is almost invariably found as a single heterosexual pair within a sponge.

Distribution: Western Atlantic; Gulf of Mexico.

REMARKS: Individual $S$. bousfieldi collected from Belize and the Bahamas follow closely Chace's (1972) original description. However, we have never encountered females with a vestigial blade on the scaphocerite (and Chace's own figure does not show a definite blade). Additionally, Chace's figure of the major chela of the first pereopod shows the superior marginal protuberance curving strongly downward without being secondarily produced distally. In Belize and the Bahamas, $S$. bousfieldi is easily distinguishable from $S$. brooksi by the shape of the major chela protuberance: rounded, directed slightly downward, and produced distally in S. bousfieldi; conical, blunt distally, and slightly directed away from the palm in $S$. brooksi. The two species are also distinguishable by the typical olive green to chestnut brown color of the developing embryos and ovaries of $S$. bousfieldi in life. Synalpheus bousfieldi can be 

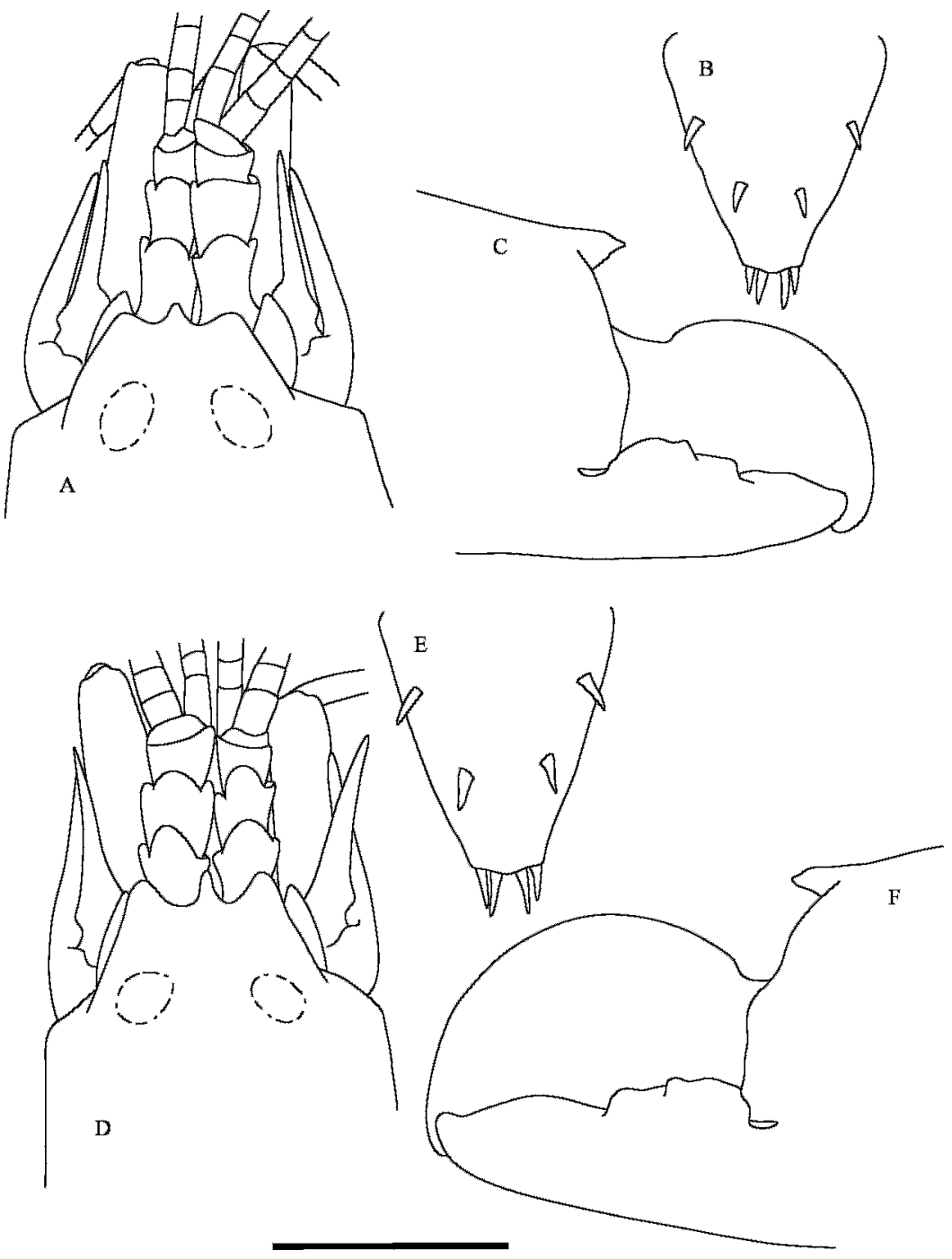

Fig. 15. Synalpheus bousfieldi. 93.47 mm (VIMS 01LS1601) from Hyatella intestinalis, G-spot, Exuma Islands, Bahamas: A, anterior region of carapace and cephalic appendages, dorsal view; B, telson, dorsal view. \$ $3.20 \mathrm{~mm}$ (VIMS 01LS1602) from H. intestinalis, G-spot, Exuma Islands, Bahamas: C, anterior region of chela of major first pereopod, lateral view. $83.13 \mathrm{~mm}$ (VIMS 03CBC1819) from $\mathrm{H}$. intestinalis, Carrie Bow Cay, Belize: D, anterior region of carapace and cephalic appendages, dorsal view; E, telson, dorsal view; F, anterior region of chela of major first pereopod, lateral view. Scale bar $=1 \mathrm{~mm}$.

distinguished from $S$. carpenteri by the pale, nondescript color, elongated lateral spines of the scaphocerite and basicerite, and by the relatively elongated telson in the former species. S. bousfieldi can be distinguished from $S$. ruetzleri by the lack of a blade on the scaphocerite.

\section{Synalpheus brooksi Coutière, 1909} figure 16

Synonymies [per Dardeau, 1984].

Material Examined: đo (VIMS 88SB5705), Aguadargana Reef, San Blas Islands, Panama, from the canals of Agelas clathrodes.,$+ 2 \pi$ 


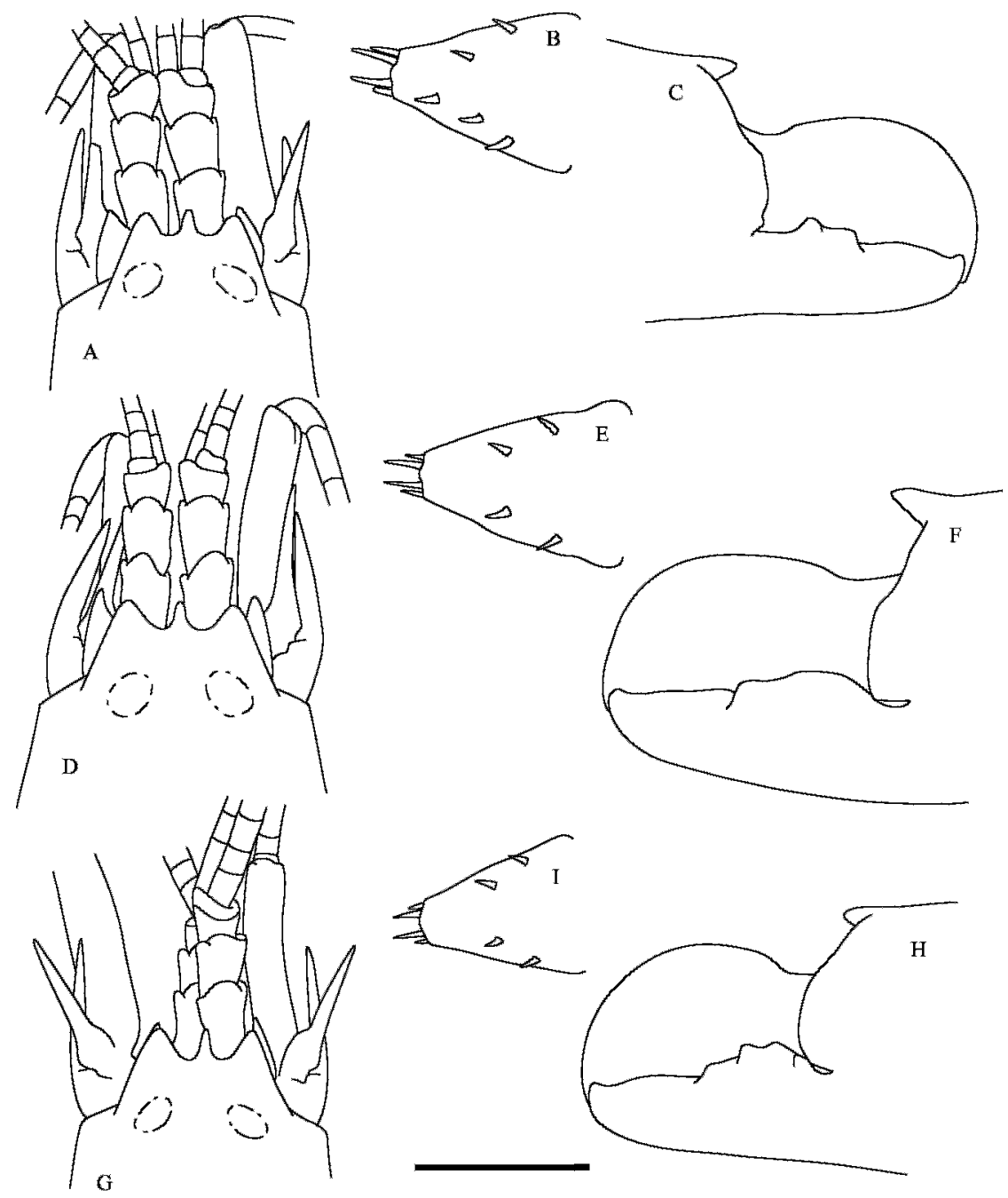

Fig. 16. Synalpheus brooksi. o $3.47 \mathrm{~mm}$ (VIMS 88SB5705) from Agelas clathrodes, Aguadargana Reef, San Blas Islands, Panama: A, anterior region of carapace and cephalic appendages, dorsal view; B, telson, dorsal view; $\mathbf{C}$, anterior region of chela of major first pereopod, lateral view. $+3.93 \mathrm{~mm}$ (VIMS 01LS0214) from Spheciospongia sp., Shark Rock, Exuma Islands, Bahamas: D, anterior region of carapace and cephalic appendages, dorsal view; E, telson, dorsal view; F, anterior region of chela of major first pereopod, lateral view. $\widehat{\delta} 3.40 \mathrm{~mm}$ (VIMS 05CBC0220) from Lissodendoryx colombiensis, Blue Ground Range, Belize: $\mathbf{G}$, anterior region of carapace and cephalic appendages, dorsal view; $\mathbf{H}$, anterior region of chela of major first pereopod, lateral view. \$ $2.82 \mathrm{~mm}$ (VIMS 05CBC0221) from L. colombiensis, Blue Ground Range, Belize; I, telson, dorsal view. Scale bar $=1 \mathrm{~mm}$.

(VIMS 93P2104-06), Limones Reef, San Blas Islands, Panama, from the canals of Lissodendoryx colombiensis. क, $\delta$ (VIMS 01LS0212, 0214), Shark Rock, Exuma Islands, Bahamas, from the canals of Spheciospongia sp. ㅇ, 8 o (VIMS 98CBC0802-10), Sand Bores, Belize, from the canals of Hyatella intestinalis.
3 oิ (VIMS 01LS1001, 1103-04), Shark Rock, Exuma Islands, Bahamas, from the canals of Hyatella sp. 2 o (VIMS 05CBC0220-21), Blue Ground Range, Belize, from the canals of $L$. colombiensis.

Color IN LIFE: Nondescript. Body transparent, with distal palm and fingers of major 
chela orange. Ovaries and developing embryos pale, ranging from green to gray to pink.

Hosts And Ecology: Synalpheus brooksi occurs predominantly in two common shallow-water sponges, Spheciospongia vesparium and Lissodendoryx colombiensis. Individuals are also found occasionally in other shrimpbearing sponge species (personal obs.; Macdonald et al., 2005). They are typically found in dense congregations of $10 \mathrm{~s}$ to $1000 \mathrm{~s}$ of individuals (Pearse, 1932, 1950; Dardeau, 1984), often with somewhat skewed sex ratios (personal obs.; Duffy 1996a), for example, 10 20 male/juvenile shrimp per mature female.

Distribution: Western Atlantic; Gulf of Mexico; Brazil.

REMARKs: Synalpheus brooksi is one of the most commonly collected species in the Gambarelloides group, mostly due to its wide geographic range and its presence in the common and easily collected loggerhead sponge, $S$. vesparium. Synalpheus brooksi is easily distinguishable from all other described species of this complex by the shape of the superior marginal protuberance of the major chela, which is bluntly conical and directed upward and slightly away from the palm.

\section{DISCUSSION}

The two new species described here are part of a complex of morphologically similar species related to $S$. brooksi and $S$. bousfieldi (Morrison et al., 2004). Together with $S$. chacei (Duffy, 1998), there are now five recognized species in this complex. The $S$. brooksi complex is taxonomically difficult due to the similarity among species and apparently strong intraspecific variation, especially among conspecifics inhabiting different host sponge species and those from distant geographic locations. Most of the intraspecific variation in this complex occurs in the two species described first, $S$. bousfieldi and $S$. brooksi, both of which are host generalists (personal obs.; Macdonald et al., 2005). In contrast, the two species described herein are host specialists. Further investigation may well reveal additional species in the brooksi complex with more restricted host use.

This study and other recent work (Ríos, 2003) have shown that several characters traditionally used to differentiate Synalpheus species are quite variable, but that a suite of other characters can greatly facilitate identification. Chace (1972) and Dardeau (1984) differentiated $S$. bousfieldi and $S$. brooksi primarily by the position of the anterior pair of dorsal spines on the telson: very close to the lateral margin in $S$. bousfieldi and distinctly removed in $S$. brooksi. We have found continuous variation in this character in both species, especially in $S$. brooksi (compare $S$. bousfieldi [figs. 14. 15] with $S$. brooksi [fig. 16]), thus rendering it unreliable. A more consistent character distinguishing $S$. bousfiel$d i$ and the two species described herein is the shape of the protuberance on the palm of the major chela. In these three species the protuberance takes the form of a somewhat rounded tubercle with a secondarily produced distal point, usually directed slightly downward toward the palm of the chela. In contrast, the protuberance in $S$. brooksi is consistently conical and blunt distally and it points slightly upward in lateral view, away from the chela palm. Within the $S$. brooksi complex, $S$. carpenteri is easily discernable by its orange coloration in life, short lateral spines of the scaphocerite and basicerite, and squat telson, while $S$. ruetzleri is recognizable by the presence of a well-developed blade on the scaphocerite. Chace (1972) mentioned the presence of a vestigial blade on the scaphocerite of female $S$. bousfieldi, but we have not found this to be the case in any of the specimens examined by us.

One interesting aspect of the ecology of sponge-dwelling Synalpheus shrimp is the presence of a variety of social structures, ranging from pair-forming species to highly eusocial species that are most easily recognizable by their extreme sex ratios. The $S$. brooksi group is the only group of closely related Synalpheus species studied to date that displays the entire range of sociality. The two species described herein, as well as $S$. bousfiel$d i$, are typically found in pairs or in groups of at most tens of individuals, with equal sex ratios. Synalpheus brooksi is more social, typically found in groups of $10 \mathrm{~s}$ to $1000 \mathrm{~s}$, and displays a skewed sex ratio (Duffy, 1996a), averaging 10-20 male and juvenile individuals for each mature female. 
Synalpheus chacei is eusocial, with colonies of up to $200+$ individuals, usually with only a single female. The improved taxonomy resulting from separation of the species described herein, as well as others in the Gambarelloides group (Duffy, 1996b; Ríos, 2003) should facilitate our understanding of the evolutionary history of these interesting social organizations.

\section{ACKNOWLEDGMENTS}

We are grateful to the Smithsonian Institution's Caribbean Coral Reef Ecosystem (CCRE) program and the National Science Foundation (DEB-9201566, DEB-9815785, IBN-0131931) for long-term support of our Caribbean Synalpheus research. Well-deserved thanks go to Mike Carpenter and Klaus Ruetzler and the Pelican Beach Resort staff for making our research at Carrie Bow Cay, Belize, possible and enjoyable. We also thank our collaborators Ruben Ríos, Eva Tóth, and Cheryl Morrison for immeasurable assistance over the years. We are grateful to Mark Siddall for advice, extensive laboratory assistance, and an essential review of this manuscript. We thank Michelle Nestlerode and Geoff Keel for diving and collecting assistance. Finally, we acknowledge the Lincoln Ellsworth Fund at the American Museum of Natural History for monetary support for K.S.M. This is contribution 770 of the CCRE, and contribution 2768 of the Virginia Institute of Marine Science, The College of William and Mary.

\section{REFERENCES}

Beebe, W. 1928. Beneath tropic seas. A record of diving among the coral reefs of Haiti. New York: Blue Ribbon Books.

Bruce, A.J. 1976. Shrimps and prawns of coral reefs, with special reference to commensalism. In O.A. Jones and R. Endean (editors), Biology and geology of coral reefs. Vol. III, Biology 2: 37-94. New York: Academic Press.

Chace, F. 1972. The shrimps of the SmithsonianBredin Caribbean expeditions with a summary of the West Indian shallow-water species (Crustacea: Decapoda: Natantia). Smithsonian Contributions to Zoology 98: 1-179.

Chace, F. 1988. The caridean shrimps (Crustacea: Decapoda) of the Albatross Philippine expedi- tion, 1907-1910, Part 5: Family Alpheidae. Smithsonian Contributions to Zoology 466: 1-99.

Coutière, H. 1908. Sur les Synalphées americaines. Comptes rendus hebdomadaires des séances de l'Académie de Sciences 146: 710-712.

Coutière, H. 1909. The American species of snapping shrimps of the genus Synalpheus. Proceedings of the United States National Museum 36: 1-93.

Dardeau, M.R. 1984. Synalpheus shrimps (Crustacea: Decapoda: Alpheidae). I. The Gambarelloides group, with a description of a new species. Memoirs of the Hourglass Cruises 7: 1-125.

Duffy, J.E. 1992. Host use patterns and demography in a guild of tropical sponge-dwelling shrimp. Marine Ecology Progress Series 90: 127-138.

Duffy, J.E. 1996a. Resource-associated population subdivision in a symbiotic coral-reef shrimp. Evolution 50: 360-373.

Duffy, J.E. 1996b. Specialization, species boundaries, and the radiation of sponge-dwelling alpheid shrimp. Biological Journal of the Linnean Society 58: 307-324.

Duffy, J.E. 1998. On the frequency of eusociality in snapping shrimps (Decapoda: Alpheidae), with description of a second eusocial species. Bulletin of Marine Science 62: 387-400.

Duffy, J.E. 2003. The ecology and evolution of eusociality in sponge-dwelling shrimp. In $\mathrm{T}$. Kikuchi (editor), Genes, behavior, and evolution in social insects: $1-38$. Sapporo: University of Hokkaiko Press.

Felder, D.L., and A.H. Chaney. 1979. Decapods crustacean fauna of Seven and One-Half Fathom Reef, Texas: species composition, abundance, and species diversity. Contributions in Marine Science 22: 1-29.

Macdonald, K.S., J.E. Duffy, and R. Rios. 2006. Biodiversity, host specificity, and dominance by eusocial species among sponge-dwelling alpheid shrimp on the Belize Barrier Reef. Diversity and Distributions 12: 165-178.

Morrison, C.L., R. Rios, and J.E. Duffy. 2004. Phylogenetic evidence for an ancient rapid radiation of Caribbean sponge-dwelling snapping shrimps (Synalpheus). Molecular Phylogenetics and Evolution 30: 563-581.

Pearse, A.S. 1932. Inhabitants of certain sponges at Dry Tortugas. Papers from Tortugas Laboratory 28, Carnegie Institution of Washington Publication 435: 119-122.

Pearse, A.S. 1950. Notes on the inhabitants of certain sponges at Bimini. Ecology 31: 149-151.

Reed, J.K., R.H. Gore, L.E. Scotto, and K.A. Wilson. 1982. Community composition, structure, areal and trophic relationships of dec- 
apods associated with shallow- and deep-water Occulina varicose coral reefs. Studies on decapod Crustacea from the Indian River Region of Florida, XXIV. Bulletin of Marine Science. 32: 761-786.

Ríos, R. 2003. Synalpheus shrimp from Carrie Bow Cay, Belize. Systematics, phylogenetics and biological observations (Crustacea: Decapoda: Alpheidae). Ph.D. dissertation, Virginia Institute of Marine Science/School of Marine Science, The College of William and Mary: Williamsburg, $251 \mathrm{pp}$.

Rützler, K. 1976. Ecology of Tunisian commercial sponges. Tethys. 7: 249-264. 